\title{
Stabilization of heterogeneous hydrogenation catalysts for the aqueous-phase reactions of renewable feedstocks
}

\author{
Xiaoyan Liu a,b, Guojun Lan a, , Zhenqing Li a, Lihua Qian a, Jian Liu b,c, Ying Li a,\# \\ a Institute of Industrial Catalysis, Zhejiang University of Technology, Hangzhou 310032, Zhejiang, China \\ b State Key Laboratory of Catalysis, Dalian Institute of Chemical Physics, Chinese Academy of Sciences, Dalian 116023, Liaoning, China \\ c DICP-Surrey Joint Centre for Future Materials, Department of Chemical and Process Engineering, and Advanced Technology Institute, University of \\ Surrey, Guilford, Surrey, GU2 7XH, UK
}

\section{A R T I C L E I N F}

\section{Article history:}

Received 27 May 2020

Accepted 1 July 2020

Available online 22 September 2020

\section{Keywords:}

Biomass conversion

Heterogeneous catalysts

Metal catalysts

Aqueous-phase reactions

Catalyst stability

\begin{abstract}
A B S T R A C T
The conversion of biomass-derived products to fine chemicals and fuels is extremely important for the utilization of renewable energy sources. Water is not only a by-product formed during the hydrogenation of biomass-derived oxygenated chemicals, but also an inexpensive and nontoxic solvent. The instability of solid catalysts for aqueous-phase reactions caused by metal leaching and the collapse of a catalyst support represents a significant challenge. In this work, various catalyst stabilization strategies including the nanospace and interfacial confinements that prevent sintering and leaching of metal nanoparticles as well as modification methods for increasing the support stability are summarized and systemically discussed. In addition, feasible approaches to designing stable and efficient heterogeneous catalysts for aqueous-phase reactions are proposed.
\end{abstract}

(C) 2021, Dalian Institute of Chemical Physics, Chinese Academy of Sciences. Published by Elsevier B.V. All rights reserved.

\section{Introduction}

Non-renewable fossil fuels (coal, crude oil, and natural gas) constitute more than $90 \%$ of the currently used energy sources. As the energy demand gradually increases and the supply of fossil fuels decreases, the utilization of renewable energy sources (wind, solar radiation, geothermal sources, hydropower, and biomass) as promising alternatives to fossil fuels represents a practically feasible strategy [1]. Biomass is an abundant, renewable, and economic agricultural resource, which can be converted to liquid fuels and high value-added chemicals through industrial reactions, such as hydroxylation, hydrogenation, and oxidation. Moreover, biomass may not only produce a wide range of valuable functionalized chemicals and high energy density fuels, but also help to protect the environ- ment and increase the economic benefits of agriculture [2,3].

Catalytic conversion in liquid solvents is one of the universal approaches to biomass utilization. Generally, biomass and its derivatives have large amounts of oxygen-containing groups that generate water as an inevitable by-product during the conversion process. In addition, water has abundant reserves and is widely available, green, and environmentally friendly, which can reduce the cost of biomass conversion. Therefore, choosing water as the solvent is a reasonable and practical approach. Catalysts are indispensable for biomass conversion, and both homogeneous and heterogeneous catalysts can be used for this purpose. However, homogeneous catalysts are difficult to separate and recover from the aqueous reaction system, whereas heterogeneous catalysts have a higher industrial application potential in the field of biomass conversion

\footnotetext{
* Corresponding author. E-mail: languojun@zjut.edu.cn

\# Corresponding author. Tel: +86-571-88320766; Fax: +86-571-88320259; E-mail: liying@zjut.edu.cn

This work was supported by the National Natural Science Foundation of China (21908197).

DOI: 10.1016/S1872-2067(20)63699-3 | http://www.sciencedirect.com/science/journal/18722067 | Chin. J. Catal., Vol. 42, No. 5, May 2021
} 
because solids are easily recovered and reused. Therefore, heterogeneous catalysts have been widely employed in biomass conversion reactions. Metal catalysts are heterogeneous catalysts that are often fabricated in the form of metal nanoparticles (MNPs) serving as the active sites for the conversion of biomass-derived compounds. They are generally made of the metals from groups VIII and B in the periodic table of elements, including noble metals (Pt, Pd, $\mathrm{Au}, \mathrm{Ru}, \mathrm{Rh}, \mathrm{Ir}$, and $\mathrm{Ag}$ ) and non-noble metals $(\mathrm{Cu}, \mathrm{Co}, \mathrm{Fe}$, and $\mathrm{Ni})$. However, the catalytic activity and stability (reusability) of the metal catalysts utilized in biomass aqueous reactions are relatively low. The deactivation of a catalyst not only makes its recovery meaningless, but also increases the production cost. Hence, it is very important to design catalysts that exhibit relatively high stability in the water phase under harsh reaction conditions. In this paper, various strategies to increase catalyst's stability are considered from two aspects: stability of the active catalytic centers and stability of the catalyst support in aqueous systems.

\section{Role of water in biomass conversion}

To improve the competitiveness of biomass relative to fossil fuels, a simple, efficient, and inexpensive process for its catalytic conversion into fuels and fine chemicals must be developed [4]. In such a process, the utilized solvent not only dissolves other components, but also promotes chemical reactions [5]. Biomass feedstock with oxygen-containing functional groups (such as hydroxyl groups) usually generates a water by-product in addition to the main products during the catalytic conversion process [6]. Because the majority of biomass components and related products are water-soluble, the corresponding reactions involving the chemicals extracted from biomass are conducted in water to efficiently solubilize reaction intermediates and products. Furthermore, water is abundant, non-toxic, cost-efficient, non-flammable, and environmentally friendly, which are important characteristics for the successful biomass conversion. In addition to reducing the environmental impact of biomass-derived chemical synthesis, the use of water as a reaction medium also benefits chemical industry by simplifying operations, such as the product separation from the aqueous-phase mother liquor [7].

Apart from serving as a reaction medium, water plays other important roles in chemical reactions [5,8-10]. For instance, in the majority of heterogeneously catalyzed processes, the hydrogen bonds formed with water molecules act as either reaction promoters or reaction inhibitors. This phenomenon is often unrecognized or underestimated; however, it is critical for the proper understanding of the biomass conversion mechanism [11]. According to the results of previous studies, water can reduce the energetic span of a reaction pathway [12] and act as a molecular catalyst to promote the conversion reaction [13]. As a typical example, the catalytic activity of Ru during the hydrogenation of ketones under gas phase conditions is lower than those of Pd and Pt. However, in the aqueous phase, $\mathrm{Ru}$ becomes more catalytically active toward the hydrogenation of ketone groups during the conversion of levulinic acid to gamma-valerolactone as compared with Pd and Pt catalysts. In the proposed reaction mechanism, the H-bonded water molecules dramatically reduce the energetic span of the reaction pathway, thus enhancing the catalytic activity of $\mathrm{Ru}$ [14].

Moreover, water can serve as a hydrogen donor in hydrogenation reactions. The presence of water may also change the adsorption type and lower the reaction energy barrier. For instance, Ren and co-workers [15] found that no benzoic acid (BA) conversion occurred when hexane was used as the solvent and $\mathrm{Ru} / \mathrm{SiO}_{2}$ (FDU) as the catalyst. However, after adding 1 $v / v \%$ water to hexane, a $50 \%$ BA conversion was achieved. Increasing the water volume fraction to $10 \mathrm{v} / \mathrm{v} \%$ increased the BA conversion to $99 \%$ (Fig. 1(a)). The results of density functional theory (DFT) calculations presented in Figs. 1(b) and (c) show that $\mathrm{H}_{2} \mathrm{O}$ easily dissociates into $\mathrm{O}^{*}$ and $\mathrm{H}^{*}$ species on the $\mathrm{Ru}$ (0001) surface with a free energy gain of $0.97 \mathrm{eV}$ until an equilibrium coverage of 5/6 monolayer is reached. The generated $0^{*}$ species strongly passivate the $\mathrm{Ru}$ surface, contributing to a significant decrease in the adsorption free energy of molecular BA. The $\mathrm{H}^{*}$ species from the dissociated $\mathrm{H}_{2} \mathrm{O}$ participate in the reaction as well. As a result, the dissociation of $\mathrm{H}_{2} \mathrm{O}$ on the $\mathrm{Ru}$ (0001) surface weakens the interactions between BA and the catalyst surface and thereby lowers the reaction energy barriers. Hence, water plays important roles in chemical reactions in addition to serving as a reaction medium.

Apart from these beneficial properties of the water medium, the latter also produces a strong effect on the reaction selectivity. Olacy and co-workers [16] studied the hydrogenation of acetic acid, which generated four main products: ethanol, CO, $\mathrm{CO}_{2}$ and $\mathrm{CH}_{4}$. After increasing the concentration of co-fed water, the ethanol selectivity was mildly increased (mainly at the expense of $\mathrm{CH}_{4}$ ), and the conversion of acetic acid remained almost constant, which was attributed to the positive effect of water that stabilized the ethanol. The high affinity of ethanol toward water increased its stability with respect to $\mathrm{CO}_{2}$ and alkanes, which were thermodynamically less stable in the aqueous phase than ethanol. A similar phenomenon was observed during the hydrogenation of furfural because the solvent affected the reaction kinetics $[17,18]$. Hronec and co-workers [19] reported that when water was used as the solvent, the main hydrogenation products were cyclopentanone $(40.23 \%)$ and cyclopentanol $(36.23 \%)$. However, furfural alcohol (47.86\%) and 2-methylfuran were the main products of the hydrogenation reaction conducted using n-butanol solvent. Moreover, Jia and co-workers [20] obtained similar results for pure methanol, methanol-dominated, and water-dominated solutions; the main products in these three cases were furfural alcohol, tetrahydrofurfuryl alcohol, and cyclopentanone, respectively.

It is necessary to consider the presence of water during the conversion of biomass-derived chemicals because biomass is always oxygenated, and water represents the main by-product of the biomass conversion process [2]. Hence, the aqueous-phase processing of biomass-derived chemicals represents a feasible strategy to convert biomass-derived chemicals into high-quality liquid fuels. The conversion of biomass-based molecules to fuels and chemicals involves various reactions, such as hydrogenolysis (C-C and C-O bonds), hydrogenation, 
A

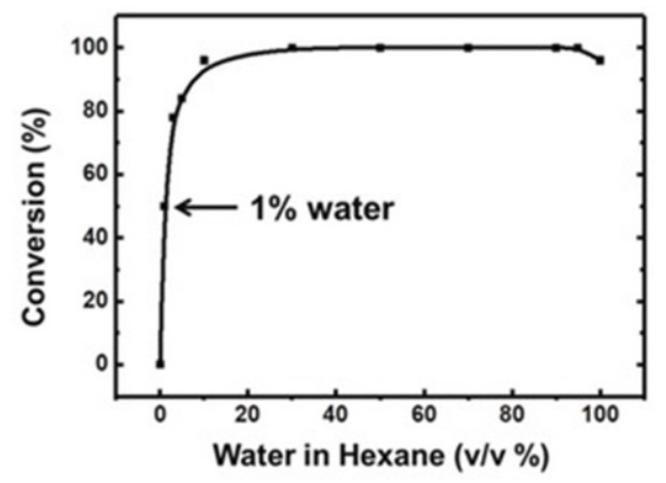

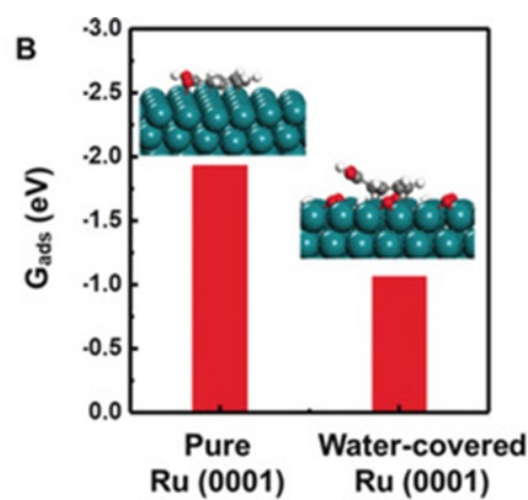

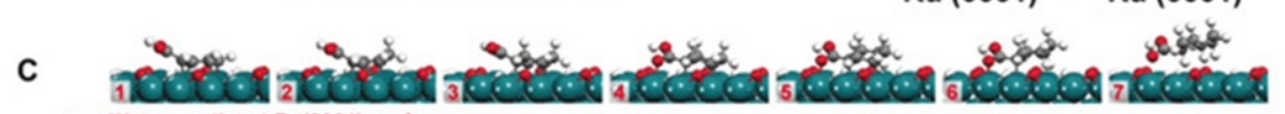

0.5 Water-mediated $\mathrm{Ru}(0001)$ surface

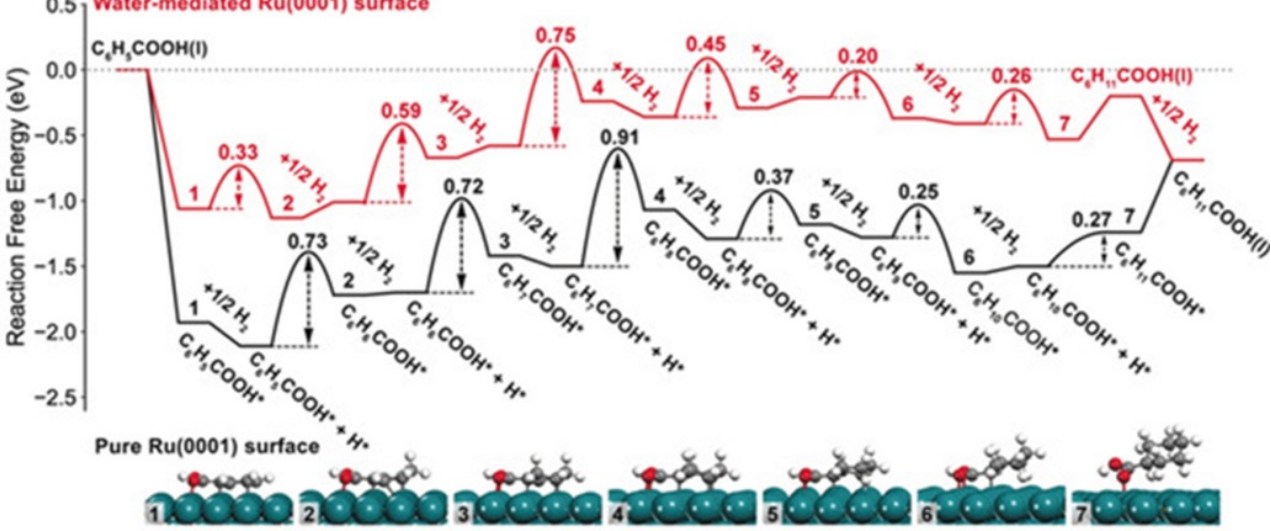

Fig. 1. (a) Conversion of BA over Ru/FDU catalyst as a function of the solvent composition (water/hexane). (b) Adsorption free energies of BA on the pure and water-mediated Ru (0001) surfaces. (c) DFT-calculated reaction paths of the BA hydrogenation on the water-mediated (red) and pure (black) $\mathrm{Ru}(0001)$ surfaces. During the first hydrogenation step on the water-mediate surface, one $\mathrm{H}^{*}$ atom is consumed from the adsorbed $\mathrm{H}_{2} \mathrm{O}$. The insets display the atomic structures of the reaction intermediates. The red, grey, white, and dark cyan spheres represent $\mathrm{O}, \mathrm{C}, \mathrm{H}$, and Ru atoms, respectively. Reproduced with permission from Ref. [15]. Copyright 2019, Wiley-VCH.

isomerization, and selective oxidation. Among these reactions, catalytic hydrogenation, including the hydrogenation of $\mathrm{C}=\mathrm{C}$, $\mathrm{C} \equiv \mathrm{C}$, and $\mathrm{C}=\mathrm{O}$ bonds, is one of the key biomass processing reactions [21], while Pt [22-24], $\mathrm{Pd}$ [25-27], $\mathrm{Ru}$ [28-33], $\mathrm{Au}$ [34-37], Co [38-44], Ni [45,46], Cu [47-54], and Fe [55] are utilized as the highly active catalytic components. During the aqueous-phase hydrogenation of biomass-derived chemicals, hydrogen gas is typically used as the $\mathrm{H}$ donor, as a result, the hydrogenation process corresponds to a three-phase heterogeneously catalyzed gas-liquid-solid reaction. However, this reaction is very complex and exhibits several drawbacks related to the catalyst design, synthesis procedure, loss of active materials, and collapse of the catalyst support. Therefore, in this review, we focus on the latest progress in the development of fabrication strategies for the highly stable and active catalysts utilized in aqueous-phase catalytic reactions, which include surface modification, carbon coating, and new catalyst design. Afterwards, directions of future research studies on the highly stable heterogeneous catalysts for the aqueous-phase hydrogenation processes are discussed.

\section{Catalyst deactivation in the aqueous phase}

The aqueous-phase catalytic conversion of biomass has sig- nificant environmental and economic potentials for producing high-quality liquid fuels and fine chemicals. In addition, the utilization of water as the reaction medium satisfies the principles of green chemistry. However, the aqueous medium of a heterogeneously catalyzed reaction also produces negative effects on the catalyst stability, which prevents its industrial implementation. Before discussing the design and preparation of catalysts for the heterogeneous aqueous-phase catalytic hydrogenation reactions, various mechanisms of the catalyst deactivation in the aqueous phase are briefly described.

The deactivation of heterogeneous catalysts in the liquid phases of organic and aqueous systems has been widely described in the literature [56]. The catalyst deactivation in the aqueous phase considerably differ from the similar processes occurring in organic solvents. Four basic catalyst deactivation mechanism exist: (1) thermal sintering of metal particles, (2) poisoning of the catalyst active sites due to water oxidation, (3) leaching of the active components dissolved in the reaction medium, and (4) collapse of the catalyst support caused by its erosion in water.

\section{1. $\quad$ Sintering of metal nanoparticles (MNPS)}

Generally, the active centers for catalytic hydrogenation 
consist of zerovalent metals. MNPs dispersed on the surface of an oxide or other support can be much more catalytically active and selective than bulk particles. The high surface area-to-volume ratio of MNPs ensures the abundance of active sites. Decreasing the size of MNPs significantly increases their specific catalytic activity. Thus, small sizes of metal particles not only make their surface atoms dynamically active, but also allow their full utilization. However, sintering of MNPs corresponding to the thermodynamically driven growth of their crystals [57] caused by a surface area loss or collapse of the catalyst support. The support dissolution process is also promoted by the high water temperature during the reaction; as a result, the catalytic component becomes unstable and increases its crystallite size, which inevitably decreases the number of active sites. For example, the sintering of Pt NPs supported on $\mathrm{Al}_{2} \mathrm{O}_{3}$ increased their size from $4.3 \mathrm{~nm}$ to $7.8 \mathrm{~nm}$ after the reaction [58]. In practical applications, the deactivation of catalysts is more complex and involves more than one deactivation mechanism.

\subsection{Oxidation of MNPs}

During the aqueous catalytic hydrogenation, metal catalysts can be easily oxidized, especially at high temperatures. The negative effect of water is related to the formation of inactive metal oxides or irreducible metal species. In the case of Fe catalysts, the presence of water resulted in the catalyst deactivation via oxidation and/or sintering. The oxidation of iron NPs by water leading to the formation of $\mathrm{Fe}_{3} \mathrm{O}_{4}$ species was observed at low water partial pressures [59]. Co-based catalysts are more stable in water than Fe-based catalysts because Co is more difficult to oxidize, which increases the probability of a successful Co-catalyzed aqueous-phase Fischer-Tropsch synthesis $[60,61]$.

\subsection{Leaching of MNPS}

The leaching phenomenon is often observed for the reactions conducted in aqueous media. It involves the solubilization or dissolution of active components in the reaction medium due to the formation of their surface carboxylate complexes [44]. The leaching of the active phase is fatal for the catalytic process because it can contaminate the final products and make catalyst recycling meaningless. For example, Liu and co-workers [62] converted levulinic acid to gamma-valerolactone using $1 \mathrm{wt} \% \mathrm{Ru} / \mathrm{C}$ catalyst. After four reaction cycles, the loading of Ru decreased to $0.37 \mathrm{wt} \%$, and the catalyst activity decreased considerably. Similarly, Hengne and co-workers [50] prepared a $\mathrm{Cu}-\mathrm{Al}_{2} \mathrm{O}_{3}$ catalyst and used it to convert levulinic acid in a water medium. After the reaction, the color of the chemical solution changed from colorless to blue, implying that copper leaching occurred due to the formation of a copper-carboxylate complex.

\subsection{Collapse of the catalyst support}

The equilibrium constant for water ionization $\left(K_{\mathrm{w}}\right)$ is highly dependent on temperature. High temperatures increase the $\mathrm{H}^{+}$ and $\mathrm{OH}^{-}$concentrations, which can degrade the catalyst support structure [63]. The heterogeneous catalysts used in biomass conversion reactions are usually supported on porous materials with high surface areas, such as zeolites, $\mathrm{Al}_{2} \mathrm{O}_{3}, \mathrm{SiO}_{2}$, $\mathrm{TiO}_{2}, \mathrm{ZrO}_{2}$, and carbon $[24,30,44,58,64-67]$. Selecting a suitable catalyst support is very important for maintaining its stability, and any changes in the support structure (structural collapse, crystal transfer, corrosion, or surface area decrease [68]) may result in catalyst deactivation. Commercial metal oxides, such as $\gamma-\mathrm{Al}_{2} \mathrm{O}_{3}$ and $\mathrm{SiO}_{2}$, are not stable in aqueous media, especially at elevated temperatures [69,70]. Ravenelle and co-workers [58] reported that a $\gamma-\mathrm{Al}_{2} \mathrm{O}_{3}$ support gradually hydrated to form boehmite after the treatment of $\mathrm{Pt} / \gamma-\mathrm{Al}_{2} \mathrm{O}_{3}$ catalyst under aqueous conditions at $225{ }^{\circ} \mathrm{C}$, causing a dramatic decrease in the surface area. Similarly, mesoporous silica (SBA-15) suffered from the collapse of its well-ordered mesoporous structure in liquid water at $200{ }^{\circ} \mathrm{C}$, resulting in a surface area loss and structural degradation [71]. In addition, the application of zeolites in aqueous phase conversion reactions is limited by their low stability at high temperatures due to desilication (the hydrolysis of $\mathrm{Si}^{4+}$ ions). As a support degrades during the aqueous-phase reaction, its active sites cannot be further stabilized [72].

\subsection{Other catalyst deactivation processes}

Fouling, one of the most common catalyst deactivation processes, involves the deposition of chemicals on the catalyst surface [73]. These species may include reactants, principal products, by-products, and even impurities. The resultant deposition prevents easy contact of the reactants with the active sites. Guo and co-workers [74] demonstrated that the amino-dopamine molecules deposited on the surface of Ru NPs blocked their active sites, leading to catalyst deactivation. After the pyrolysis of the used catalysts under a hydrogen flow, the adsorbed amino-dopamine species decomposed; as a result, the exposure degree of Ru NPs and their catalytic activity increased simultaneously. A similar phenomenon was observed for the decomposition of formic acid in the presence of $\mathrm{Ru} / \mathrm{C}$ catalyst. Here, the CO by-product strongly adsorbed on the Ru surface, leading to the irreversible deactivation of Ru NPs [75].

\section{Stabilization strategies for the catalysts used in aqueous-phase reactions}

The hydrothermal reaction conditions are unfavorable to the hydrogenation of biomass-derived chemicals. The heterogeneous catalysts used in this process undergo deactivation due to the corrosion of their supports, sintering of the active sites, oxidation, and leaching, which decrease their hydrothermal stability. Therefore, stabilization of the aqueous phase hydrogenation catalysts is extremely important, especially under harsh reaction conditions.

As mentioned above, the deactivation mechanisms of the metal catalysts used for the biomass-derived compounds in the aqueous, high-temperature, and high-pressure systems include 
a

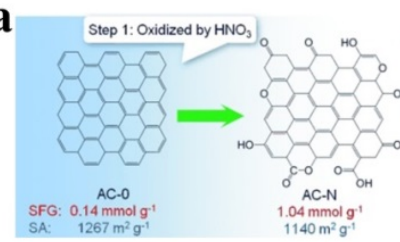

b
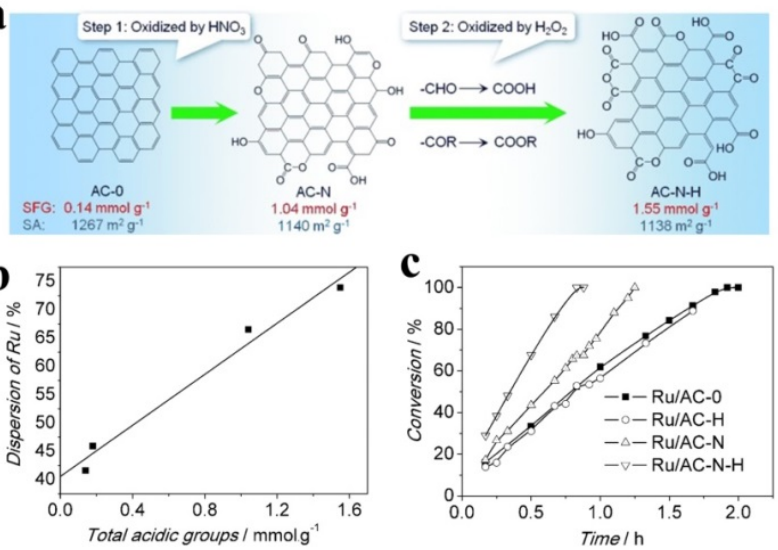

Fig. 2. (a) A scheme describing the carbon pre-treatment with surface oxygen groups by the two-step liquid oxidation method. SFG and SA denote the concentration of SFGs and surface area, respectively. (b) Dispersion of Ru NPs in Ru/AC- $x$ as a function of the total concentration of acidic SFGs on the AC surface. (c) Benzene conversion as a function of the reaction time for $\mathrm{Ru} / \mathrm{AC}-x$. Reproduced with permission from Ref. [83]. Copyright 2014, Wiley-VCH.

(1) sintering of MNPs, (2) oxidation of MNPs by water, (3) leaching of metal components, (4) poisoning of the active sites, and (5) collapse of the catalyst support [56]. Herein, we discuss various strategies for the preparation of highly stable catalysts from the following two aspects: increasing the stability of MNPs to prevent sintering or leaching and increasing the stability of the catalyst support.

\subsection{Stabilization of MNPs active sites}

\subsubsection{Modification of the catalyst support}

Carbon materials are chemically inert and have been used as supports for many heterogeneous catalysts applied to the biomass hydrogenation in the aqueous phase due to their tunable porosity characteristics and good stability in water at high temperatures [76,77]. However, the anchoring of highly dispersed MNPs on a carbon support remains a challenging task due to the inertness of the carbon matrix that weakly interacts with such NPs having high surface energy. The preparation of highly stable carbon-supported metal NPs requires strong metal-support interactions, which can be enhanced by modifying the carbon surface with organic groups. The formation of oxygen-containing groups on the carbon surface and their influence on the properties of carbon-supported catalysts have been reported in many studies [78-80]. It is generally assumed that the presence of surface oxygen groups promotes the adsorption on metal sites; in addition, the dispersion of metal particles linearly increases with the number of surface functional groups (SFGs) [81].

The chemical composition and concentration of surface oxygen functional groups can be modified through their oxidation and/or thermal treatment under inert atmosphere [82]. Our group conducted a two-step liquid oxidation treatment of activated carbon (AC) [83]. As shown in Fig. 2, the two-step liquid oxidation process involves the use of $\mathrm{H}_{2} \mathrm{O}_{2}$ after $\mathrm{HNO}_{3}$. A sufficient number of acidic functional groups (such as carboxylic groups and lactones) are introduced onto the surface of carbon materials without a loss of the carbon texture. Owing to the abundant SFGs, ruthenium NPs became highly dispersed, and their degree of dispersion increased with increasing SFG concentration (Fig. 2(b)). These catalysts exhibit high activities and stability during benzene hydrogenation (Fig. 2(c)) and can be applied to ammonia synthesis [84]. Additionally, the presence of surface oxygen groups can increase the catalyst hydrophilic-
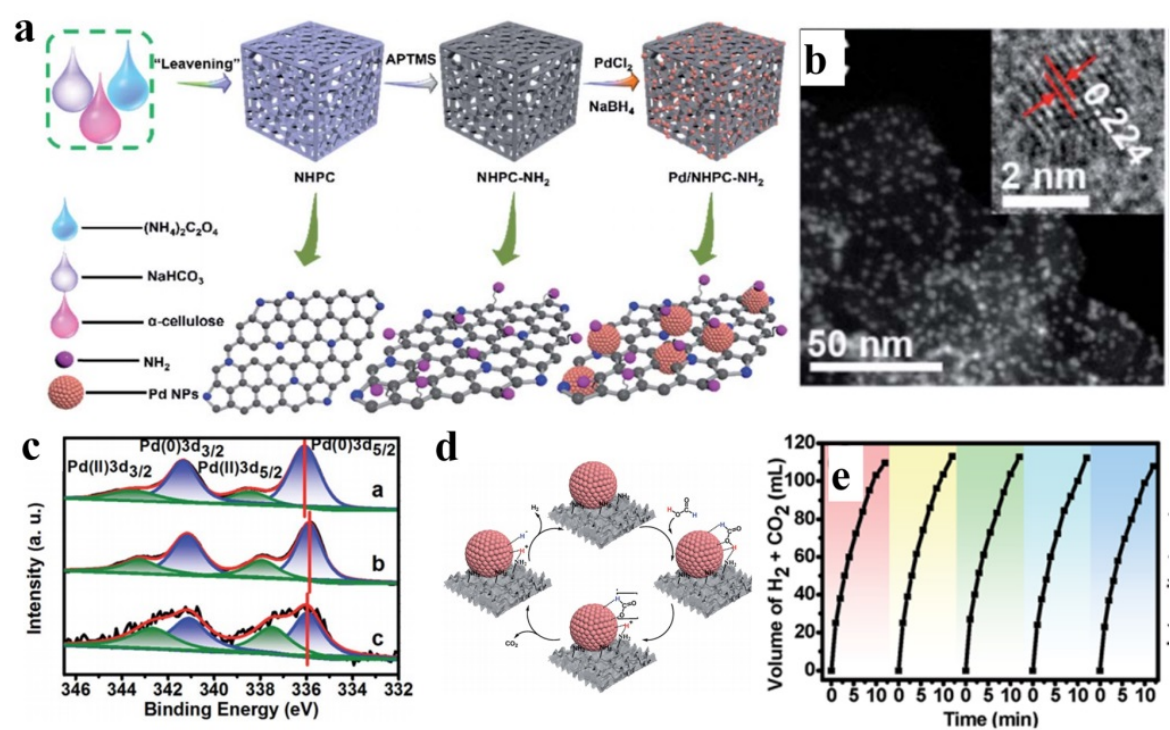

Fig. 3. (a) Schematic illustration of the preparation of Pd/NHPC- $\mathrm{NH}_{2}$ catalyst. (b) High-angle annular dark-field scanning transmission electron microscopy (HAADF-STEM) and high-resolution TEM (HRTEM) (inset) images of Pd/NHPC-NH2. (c) Pd 3d X-ray photoelectron spectra of Pd/NHPC-NH2 (a, top) and Pd/NHPC (b, medium) catalysts. (d) A possible reaction pathway for the dehydrogenation of formic acid over Pd/NHPC- $\mathrm{NH}_{2}$. (e) Recyclability of Pd/NHPC- $\mathrm{NH}_{2}$ catalyst for the dehydrogenation of formic acid. Reaction conditions: $1.0 \mathrm{M}$ of formic acid, $2.5 \mathrm{~mL}, n_{\mathrm{Pd}} / n_{\mathrm{FA}}=0.01,25^{\circ} \mathrm{C}$. Reproduced with permission from Ref. [88]. Copyright 2019, Royal Society of Chemistry. 
ity, making its surface more accessible during a aqueous-phase reaction [85]. Furthermore, these groups frequently act as nucleation centers for the generation of highly dispersed MNPs [86].

In addition to oxygen ligands, nitrogen and sulfur ligands (such as thiols, amines, disulfides, thioethers, phosphenes, and N-heterocyclic carbenes) can also be used for MNP stabilization [25]. Ferry and co-workers [87] utilized electron-rich $\mathrm{N}$-heterocyclic carbenes to stabilize Pd NPs through the formation of strong covalent bonds between the ligands and the metallic surface, which allowed these NPs to maintain their size-dependent properties. The resulting interface with confined Pd particles exhibited high long-term stability during the catalytic hydrogenation in an aqueous solution. Similarly, Wang and co-workers [88] used amino-functionalized hierarchically porous carbon as a support (Figs. 3(a) and (b)) to fabricate $\mathrm{Pd} / \mathrm{NHPC}-\mathrm{NH}_{2}$ catalyst containing small and well-dispersed Pd NPs. As shown in Fig. 3(c), the differences in the zerovalent Pd $3 d$ binding energies between Pd/NHPC- $\mathrm{NH}_{2}$ (top, panel a) and
Pd/NHPC (medium, panel b) catalysts demonstrates the existence of strong metal-support interactions. The amino groups not only anchor Pd particles, but also act as proton scavengers forming $\mathrm{OH}^{\cdots} \mathrm{N}$ bonds (Fig. 3(d)) that promote the $\mathrm{O}-\mathrm{H}$ bond dissociation leading to $\mathrm{H}^{+}$formation. Furthermore, the $\mathrm{Pd} / \mathrm{NHPC}-\mathrm{NH}_{2}$ catalyst exhibited relatively high stability without an apparent decrease in the catalyst activity after five reaction cycles, as shown in Fig. 3(e). These results indicated that the formation of covalent bonds between organic groups and metal NPs enhanced the interactions between MNPs and the carbon support.

In addition, heteroatom (N, B, P, and S)-doped carbon-supported metal catalysts demonstrated advanced characteristics because the doping procedure tailored the carbon properties $[89,90]$. The results of DFT simulations results revealed that both $\mathrm{N}$ and $\mathrm{S}$ elements enhanced the interactions between Pt and the carbon support [91]. As shown in Fig. 4, both single atoms and MNPs can be anchored on the nitrogen-doped carbon sites due to the strong metal-support inter-

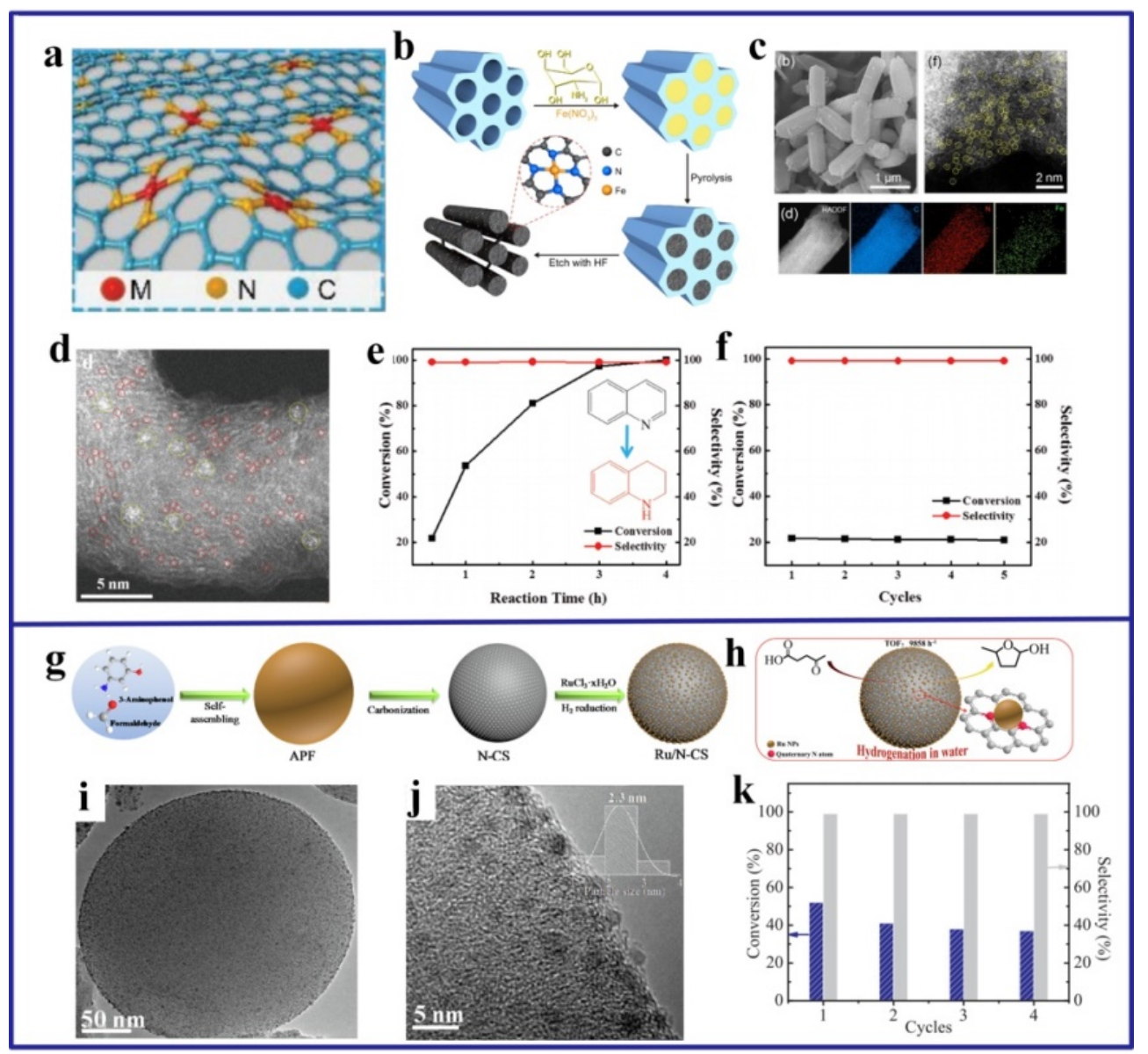

Fig. 4. (a) A nitrogen-doped carbon support for metal sites. Reproduced with permission from Ref. [92]. Copyright 2019 Wiley-VCH. (b) Schematic illustration of the synthesis route for the ordered mesoporous Fe1/N-C catalyst. (c) An SEM image, an aberration-corrected HAADF-STEM image, and energy-dispersive X-ray spectroscopy maps of Fe1/N-C catalyst. Reproduced with permission from Ref. [93]. Copyright 2019 American Chemical Society. (d) An HAADF-STEM image of Co single atoms/AC@N-CNTs. The Co clusters and single atoms are marked with the yellow and red circles, respectively. (e) Catalytic performance of Co single atoms/AC@N-CNTs during quionline hydrogenation. Reaction conditions: 5 mg of catalyst, 0.5 mmol of quionline, $5 \mathrm{~mL}$ of ethanol, $100^{\circ} \mathrm{C}, 2 \mathrm{MPa} \mathrm{H}_{2}$ pressure. (f) Reusability of Co single atoms/AC@N-CNTs-L catalyst. Reproduced with permission from Ref. [94]. Copyright 2019 Wiley-VCH. (g) Schematic illustration of the fabricated Ru/N-CS-850 catalyst. (i,j) TEM and HRTEM images of $\mathrm{Ru} / \mathrm{N}-\mathrm{CS}-850$. (k) Reusability of Ru/N-CS-850 catalyst during the hydrogenation of levulinic acid. Reaction conditions: $18 \mathrm{mg}$ of catalyst, $17.8 \mathrm{mmol}$ of levulinic acid, $20 \mathrm{~mL}$ of water, $70^{\circ} \mathrm{C}, 4 \mathrm{MPa} \mathrm{H}_{2}$ pressure, $1 \mathrm{~h}$. Reproduced with permission from Ref. [62]. Copyright 2019, Elsevier. 


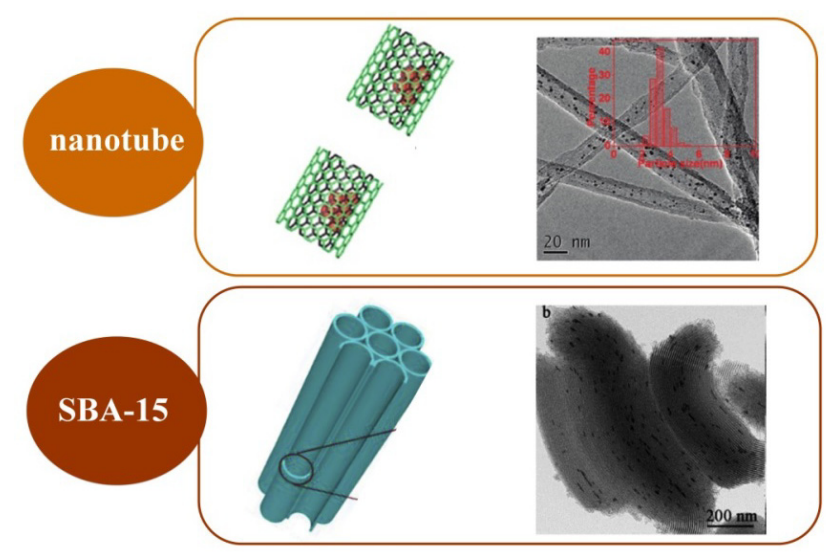

Fig. 5. MNPs confined in long channels. The image of CNTs is reproduced with permission from Ref. [97]. Copyright 2015, Oxford University Press. The image of SBA-15 is reproduced with permission from Ref. [98]. Copyright 2018, Elsevier.

action effect [62,92-94]. Gong and co-workers [94] prepared a highly dispersed Co single atoms/AC catalyst confined inside N-doped carbon nanotubes (CNTs) (Figs. 4(d)-(f)), which exhibited excellent stability during quionline hydrogenation in the water phase. Our group synthesized N-doped carbon spheres through the pyrolysis of aminophenol formaldehyde resin (APF) at $850{ }^{\circ} \mathrm{C}$ and introduced Ru NPs by the impregnation method described in Fig. 4(g) [62]. The Ru/N-CS-850 cata- lyst contained uniform and stable Ru NPs $(2.3 \mathrm{~nm})$ on its surface, and the catalytic activity of this material for the levulinic acid hydrogenation in water was evaluated. Due to the strong interactions between the nitrogen dopant and Ru NPs, the catalyst exhibited high good stability after four reaction cycles. Similar results were reported in previous works; for instance, Gao and co-workers [95] demonstrated that $\mathrm{Cu} / \mathrm{N}-\mathrm{C}$ catalyst remained stable without deteriorating its catalytic performance after five cycles of converting 2,5-dimethylfuran to 2,5-dimethyltetrahydrofuran due to the strong interactions between the $\mathrm{N}$-doped carbon support and $\mathrm{Cu}$ species. Very stable Ru NPs on a N-doped carbon support, which retained their catalytic activity during the hydrogenation of phenol and benzylic compounds, were fabricated by Cui and co-workers [96]. In addition to MNPs anchoring, $\mathrm{N}$ atoms can also facilitate the dispersion of metal particles and help them to achieve an electron-rich state, which significantly increases their activity [31].

\subsubsection{Encapsulation of MNPs in nanospace (pores, channels, and cages)}

MNPs can be stabilized by encapsulation. Porous materials (such as zeolites, CNTs, and SBA-15) have attracted much attention because their pores and channels provide voids for the catalytically active particles, which increase their stability (Fig. 5). The confined MNPs are retained inside the zeolite, CNT, or SBA-15 structure, while the long channels suppress the diffu-

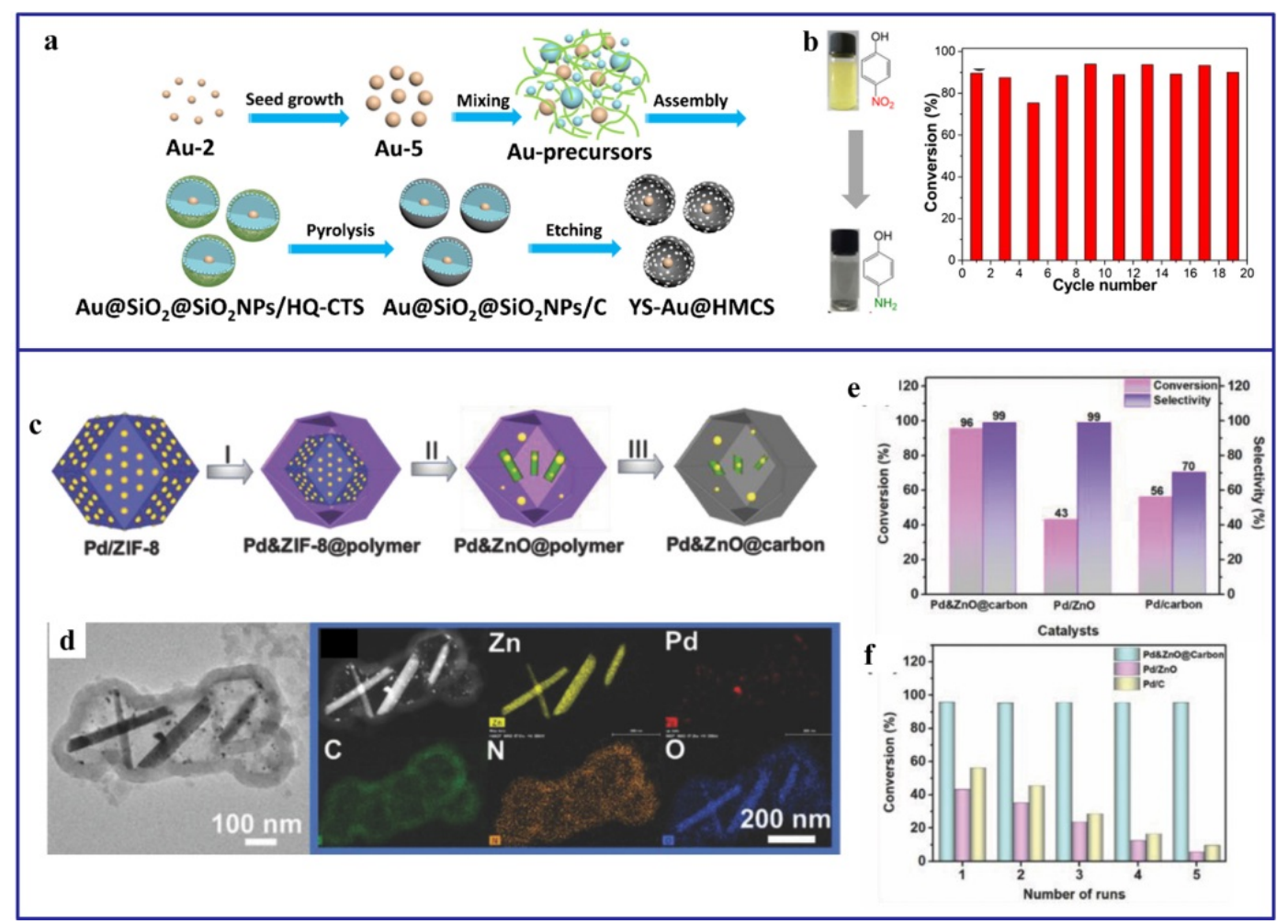

Fig. 6. (a) Schematic illustration of the synthesis of hollow yolk-shell YS-Au@HMCs nanoreactors. (b) Reusability of YS-Au@HMCs catalysts for the conversion of 4-nitrophenol. Reproduced with permission from Ref. [103]. Copyright 2018, Elsevier. (c) Schematic illustration of the fabrication of yolk-shell-structured Pd\&ZnO@carbon catalyst. The blue, purple, yellow, green, and gray colors refer to ZIF-8, the polymer layer, MNPs, ZnO particles, and the carbon layer, respectively. (d) TEM, HAADF-STEM, and elemental mapping images of Pd\&Zn@carbon. (e-f) Catalytic performance and reusability of Pd\&Zn@carbon, Pd/ZnO, and Pd/C catalysts utilized for phenylacetylene hydrogenation. Reaction conditions: $30^{\circ} \mathrm{C}, 60 \mathrm{~min}, 20 \mathrm{mg}$ of catalyst 1 bar $\mathrm{H}_{2}, 2.9 \mathrm{mmol}$ of substrate, $25 \mathrm{~mL}$ of ethanol solvent. Reproduced with permission from Ref. [100]. Copyright 2018, Wiley-VCH. 


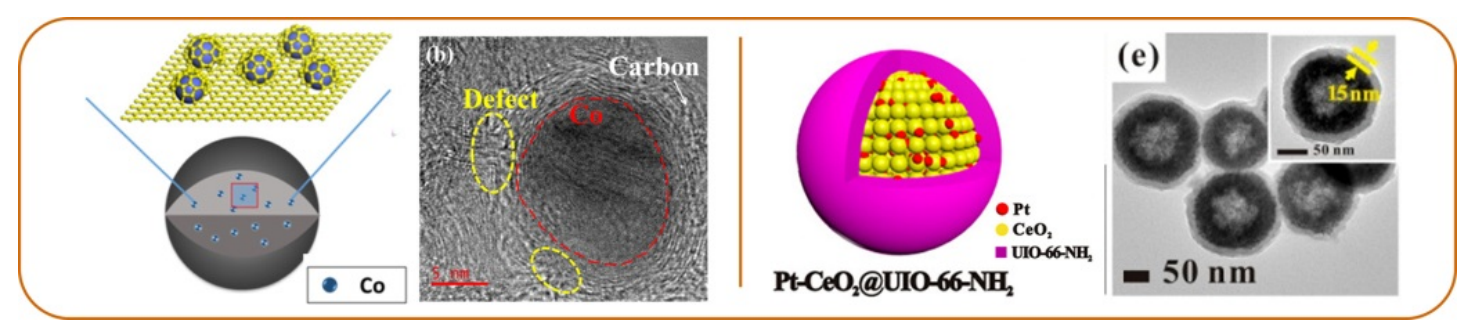

Fig. 7. Schematic diagrams of the "overcoat"-type encapsulated catalysts. Reproduced with permission from Refs. [39] and [107]. Copyright 2016/2018, American Chemistry Society.

sion of reactant and product molecules.

Monodispersed hollow carbon spheres and cages have also received much attention in the field of encapsulated catalysts due to their good dispersion properties in liquid solvents. Moreover, permeable shell not only promote the mass transportation of reactive species, but also protect the catalytically active sites against leaching even under harsh reaction conditions. Most importantly, their zero-dimensional morphology can significantly ease the diffusion restrictions for reactant molecules. As shown in Figs. 6(a), Yang and co-workers [103] synthesized Au NPs seeds and coated them by silica and chitosan layers. After the carbonization and silica etching processes, the Au NPs were successfully encapsulated by the hollow carbon spheres (denoted YS-Au@HMCS), as indicated by the corresponding SEM and TEM images. The obtained catalyst exhibited high stability during 4-nitrophenol conversion without apparent activity losses after 10 reaction cycles (Fig. 6(b)). Chen and co-workers [99] fabricated a yolk-shell Co@C-N catalyst, which consisted of a Co core anchored by an N-carbon nanosheet and a porous $\mathrm{N}$-doped carbon shell. This catalyst exhibited superior catalytic activity during the aerobic oxidation of alcohols in the water phase, was easily recovered by a magnet, and demonstrated excellent stability properties after many uses. Tian and co-workers [100,101] confined active metal (Pd) particles inside porous carbon (Figs. 6(c), (d)); the prepared catalysts exhibited excellent stability during the hydrogenation of phenylacetylene to phenylethylene and nitrobenzene to aniline in a liquid phase without significant deactivation after five reaction cycles, as shown in Figs. 6(e), (f). Similarly, after coating an ultrathin graphene nanoshell, the as-prepared Au@HGN catalyst possessed exceptional catalytic activity and recycling ability during the catalytic reduction of 4-nitrophenol to 4-aminophenol as compared with the corresponding parameters of $\mathrm{Au} / \mathrm{TiO}_{2}$ catalyst used as a control [102].

\subsubsection{Coating MNPs with ultrathin layers}

Another efficient strategy for preventing active metal species from leaching and sintering involves encapsulating MNPs within a protective "armor", such as a carbon layer [39,43,104-106] and metal-organic frameworks (MOFs) (Fig. 7) [107]. The two-dimensional graphene structure possesses enhanced protective properties, and Deng's group labeled it "chainmail for catalysts" [108,109]. This strategy can be applied

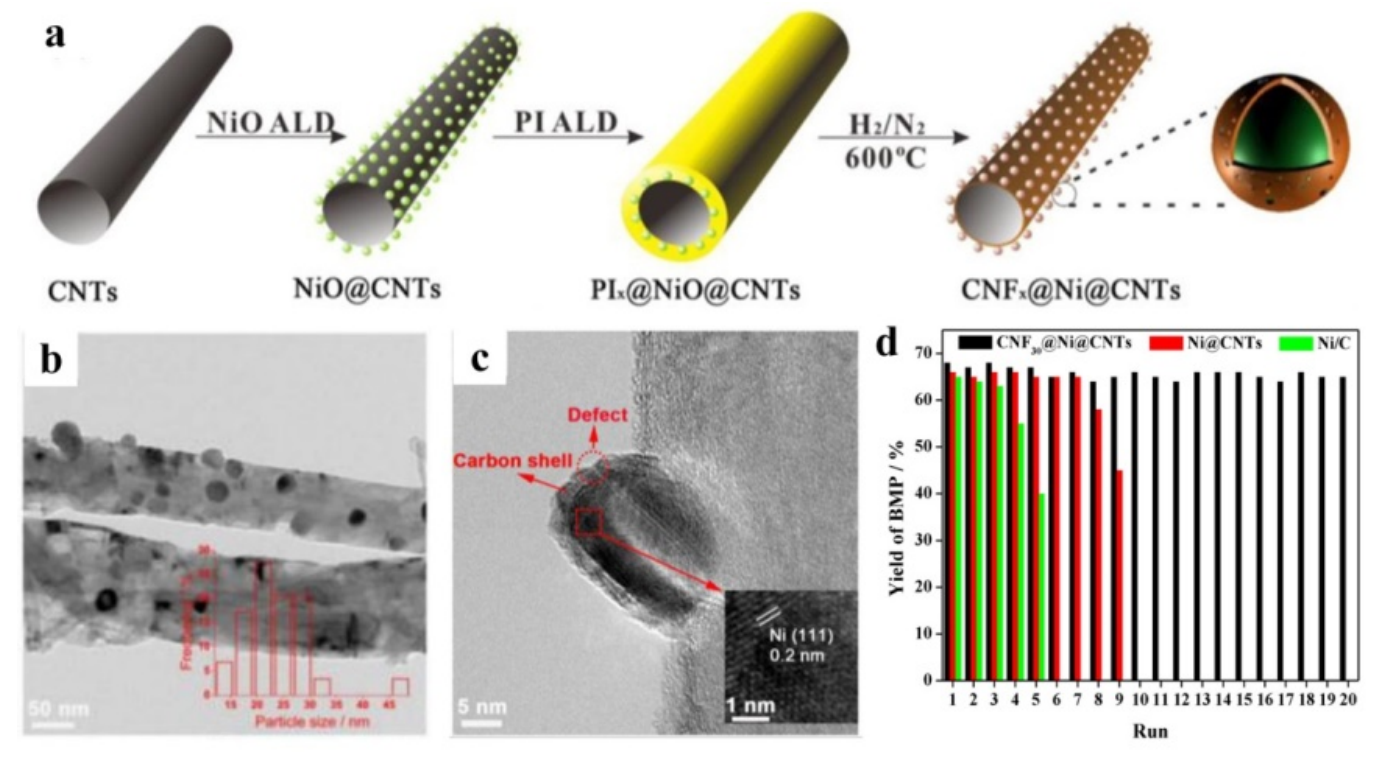

Fig. 8. (a) Illustration of the catalyst preparation procedure. (b,c) TEM images of $\mathrm{CNF}_{30} @ N i @ C N T$ catalyst. (d) Results of the catalyst reuse study conducted for the reductive aminantion of levulinic acid with benzyl amine over $\mathrm{CNF}_{30} @ \mathrm{Ni} @ \mathrm{CNT}$ (black), Ni@CNT (red), and Ni/C (green) catalysts. Reaction conditions: $10 \mathrm{mmol}$ of levulinic acid, $10 \mathrm{mmol}$ of benzyl amine, $0.03 \mathrm{~g}$ of catalyst, $10 \mathrm{wt} \% \mathrm{of} \mathrm{Ni}, 4 \mathrm{~mL}$ of gamma-valerolactone solvent, 3.0 $\mathrm{MPa}_{2}, 130^{\circ} \mathrm{C}$, and $4 \mathrm{~h}$. Reproduced with permission from Ref. [104]. Copyright 2017, American Chemistry Society. 
to protect NPs with ultrathin carbon layers.

Gao and co-workers [104] developed an atomic layer deposition (ALD) method for the synthesis of porous carbon-coated Ni NPs supported on CNTs for the reductive amination of levulinic acid to pyrrolidones (Fig. 8). Compared with the "naked" $\mathrm{Ni}$ NPs loaded on the CNT surface, the obtained $\mathrm{CNF}_{30} @ \mathrm{Ni} @ \mathrm{CNT}$ catalyst was very stable and could be reused up to 20 times without $\mathrm{Ni}$ leaching. In addition, Wei and co-workers [39] coated Co NPs onto porous graphene layers. The resulting $\mathrm{CoO}_{x} @ \mathrm{CN}$ material successfully catalyzed the hydrogenation of quinolone to tetrahydro quinolone in water. After being recycled 12 times, the catalyst retained its original high activity. The excellent stability of $\mathrm{CoO}_{x} @ \mathrm{CN}$ was attributed to the stable and intact encapsulation structure, which could considerably reduce the extent of leaching and prevent Co NPs from growing.

\subsubsection{Embedding MNPs inside a matrix}

Structural embedment refers to a partial or full "immersion" of metallic MNPs into the support. Embedded MNPs can be strongly adhered to the support and become more stable than the MNPs loaded onto the support surface. Liu and co-workers
[76] and Wang and co-workers [110] mixed metallic precursor with aminophenol formaldehyde resin spheres and chitosan followed by carbonization to obtain an embedded catalyst, as shown in Figs. 9(a)-(e). The corresponding TEM images contained highly dispersed MNPs. However, the catalytic performance of this catalyst was very poor because a fraction of these NPs was completely coated by the carbon substrate. Therefore, the accessibility of the catalyst active sites for the reactant molecules must be considered.

The semi-embedded part of the NPs was "bitten", while their other part was exposed, which ensured the accessibility of the active sites for reactant molecules. As shown in Fig. 9(f), our group fabricated a confined catalyst with a semi-embedded structure [111-113]. In particular, we embedded $\mathrm{SiO}_{2}$ spheres into $\mathrm{a} \mathrm{Ru}^{3+}$ ion precursor followed by coating the resulting $\mathrm{Ru}^{3+}-\mathrm{SiO}_{2}$ composite with sucrose (Fig. 9(f)). After the carbonization under $\mathrm{N}_{2}$ flow and etching of the $\mathrm{SiO}_{2}$ hard template, the in-situ formed Ru NPs were partially embedded into carbon. The semi-embedded Ru-C catalyst was used for the hydrogenation of BA and levulinic acid in water. The obtained results showed the excellent catalyst stability and absence of $\mathrm{Ru}$ leaching or sintering after five reaction cycles (Figs. 9(g)-(i)).

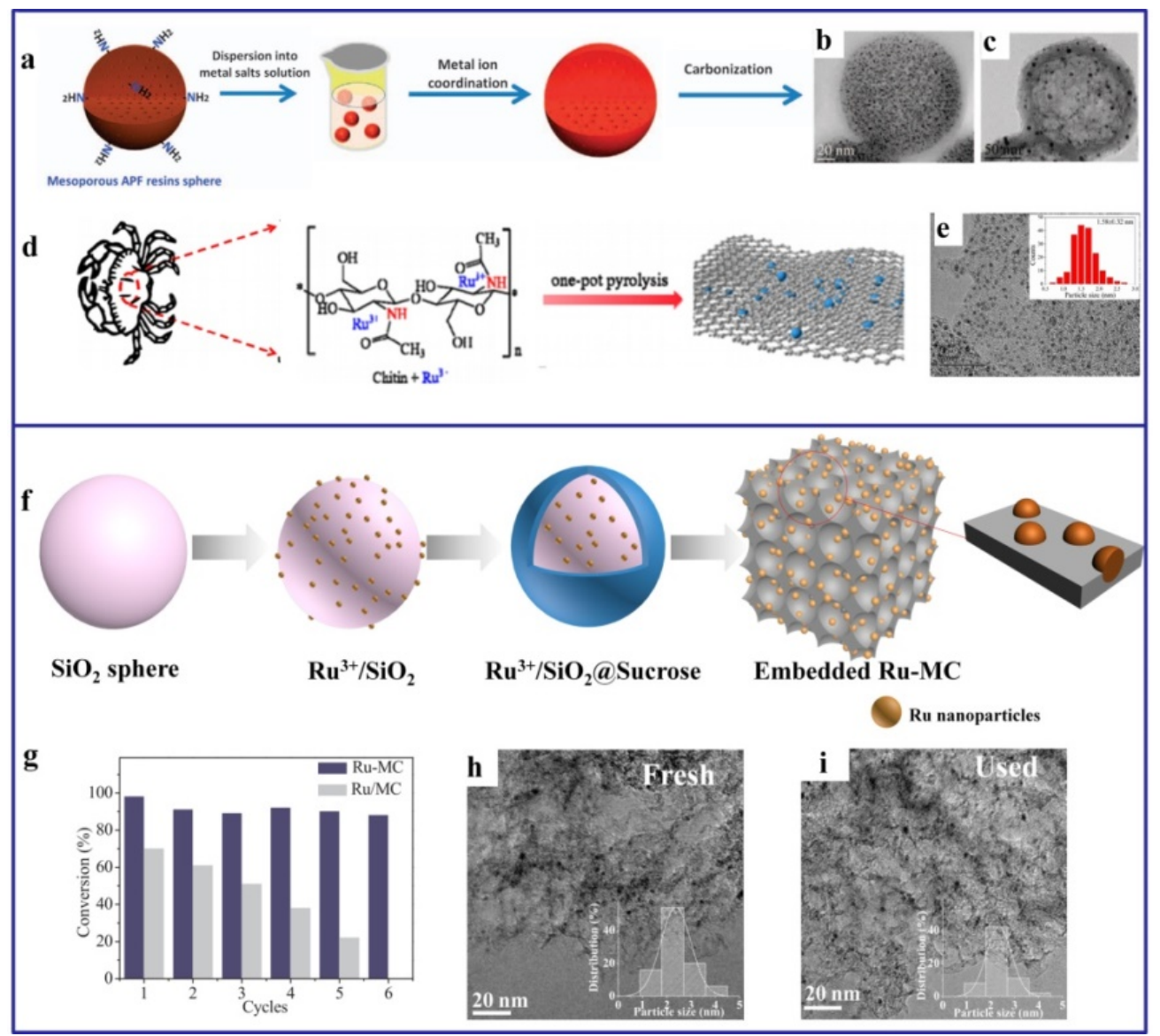

Fig. 9. (a-c) Schematic illustration and TEM images describing the formation of carbon-embedded metal spheres. Reproduced with permission from Ref. [76]. (d,e) Schematic illustration and TEM image describing for formation of the carbon-embedded MNPs. Carbon precursor: chitosan. Reproduced with permission from Ref. [110]. Copyright 2018, American Chemistry Society. (f) Schematic illustration of the formation of Ru spheres semi-embedded in mesoporous carbon (Ru-MC). (g) Reusability of Ru-MC catalyst for levulinic acid conversion. TEM images of the (h) fresh and (i) used Ru-MC catalysts. Reaction conditions: $17.8 \mathrm{mmol}$ of levulinic acid, $18 \mathrm{mg}$ of catalyst ( $2 \mathrm{wt} \%), 70{ }^{\circ} \mathrm{C}, 4 \mathrm{MPa} \mathrm{H}_{2}, 1 \mathrm{~h}, 20 \mathrm{~mL}$ water solvent. Reproduced with permission from Ref. [111]. Copyright 2018, Elsevier. 


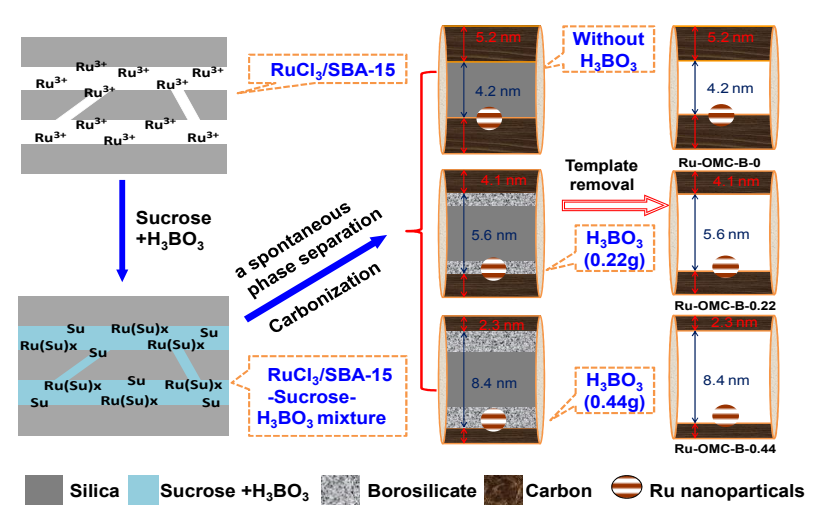

Fig. 10. Adjustments performed for the partial embedment of Ru NPs into the carbon framework of Ru-OMC catalysts. Reproduced with permission from Ref. [114]. Copyright 2014, Wiley-VCH.

The more exposed is the MNP surface, the higher is its catalytic activity. As shown in Fig. 10, our group performed a controlled synthesis of highly dispersed semi-embedding Ru NPs in a porous carbon framework with controlled embedding degrees of Ru NPs. [114]. The obtained Ru-containing ordered mesoporous carbon (Ru-OMC) catalyst demonstrated remarkably high activity and stability in the course of heterogeneous hydrogenation reactions, owing to its large exposed Ru surface area and embedment degree of Ru NPs. Here, sucrose was used as a carbon precursor, which played an important role in stabilizing $\mathrm{Ru}^{3+}$ species and acted as a reductant during further carbonization. The interaction of sucrose with $\mathrm{Ru}^{3+}$ ions and two-step carbonization process prevented sintering of noble metal particles during the high-temperature treatment, thus facilitating their dispersion. The use of $\mathrm{RuCl}_{3} / \mathrm{SBA}-15$ as the hard template instead of premixing of $\mathrm{RuCl}_{3}$ with carbon precursors increased the contact area of the majority of exposed ruthenium NPs during the catalytic reactions. Ru NPs confined in ordered mesoporous carbon (Ru-OMC) with various embedding degrees can been fabricated through a boric acid assisted hard template method. And an optimized degree of Ru NPs embedding in porous carbon framework is necessary for the best catalytic activity and stability.

The described embedment strategy for preparing highly stable catalysts has been efficiently verified by Xia and Wei's group [115]. Xia and co-workers [116] embedded Co NPs into

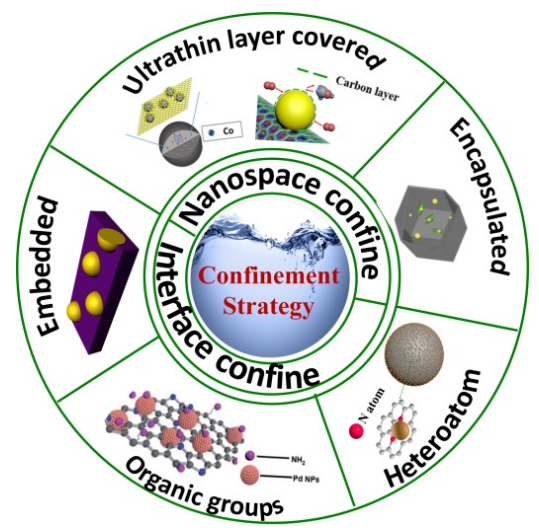

Fig. 11. Schematic overview of the MNP confinement strategy. carbon for the vanillin hydrogenation with formic acid serving as the $\mathrm{H}_{2}$ donor. The resultant Co@NC-700 catalyst exhibited highly stable properties even under harsh reaction conditions (corresponding a strongly acidic aqueous phase). Apart from carbon materials, various oxides can also be applied to fabricate embedded structures. For example, Hutchings and co-workers $[53,117]$ synthesized $\mathrm{Cu}-\mathrm{ZrO}_{2}$ catalyst by an oxalate gel precipitation method, in which $\mathrm{Cu}$ NPs were embedded into a $\mathrm{ZrO}_{2}$ support.

Fig. 11 summarizes the discussed MNPs stabilization strategies, which can be mainly classified into the interfacial and nanospace confinements. (1) In the interfacial confinement strategy, organic functional groups and $\mathrm{N}$ heteroatoms are introduced into the support to facilitate its stable coordination with MNPs via the reduction of their surface energy and enhancement of the metal-support interactions. Additionally, metal particles are embedded into the carbon matrix to not only restrict their migration, but also promote the metal-carrier interactions. (2) In the nanospace confinement strategy, MNPs are either encapsulated inside pores or cavities, or coated with an ultra-thin "armor" layer, which considerably increases their stability under harsh reaction conditions. Therefore, both the interfacial and nanospace confinement strategies can effectively prevent MNPs from sintering and leaching during the reaction process and thus improve the catalyst stability.

\subsection{Support stabilization strategies}

\subsubsection{Chemical modification}

A major challenge for the metal oxide-supported metal catalysts is the collapse and transformation of their original support structure. This problem can be solved by increasing the stability of the metal oxide support. Many studies pointed out that the support modification with another component (such as a bimetal or a promoter) might be used for this purpose due to the synergistic interaction between the support and the modifying agent $[47,118-120]$. For instance, Ma and co-workers [41] introduced a rare earth metal (La) into the $\mathrm{ZrO}_{2}$ structure to form a $\mathrm{ZrLaO}_{x}$ support followed by Co NPs loading to convert furfural to furfural alcohol in water. As shown in Fig. 12, La atoms (blue spheres) are uniformly dispersed across the $\mathrm{ZrO}_{2}$ matrix. The relatively high stability of the obtained catalyst
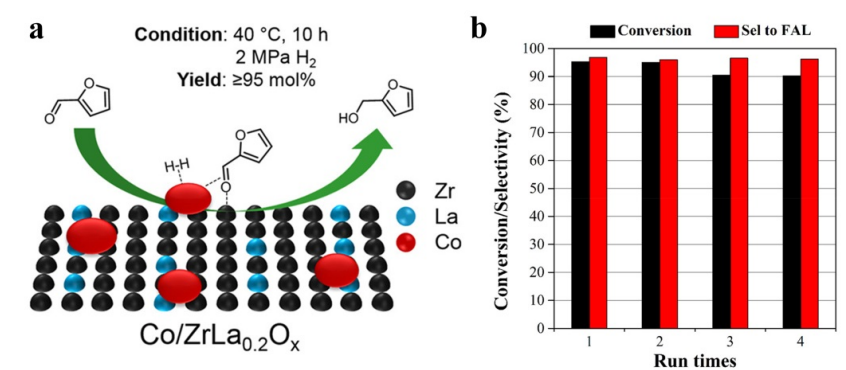

Fig. 12. (a) Schematic of the Co/ZrLa ${ }_{0.2} \mathrm{O}_{x}$ structure. (b) Effect of recycling on the catalytic performance of $\mathrm{Co} / \mathrm{ZrLa}_{0.2} \mathrm{O}_{x}$. Reaction conditions: $100 \mathrm{mg}$ of furfural, $50 \mathrm{mg}$ of $\mathrm{Co} / \mathrm{ZrLa}_{0.2} \mathrm{O}_{x}$ in $10 \mathrm{~mL}$ of water, $40^{\circ} \mathrm{C}, 2$ $\mathrm{MPa} \mathrm{H}_{2}, 10 \mathrm{~h}$. Reproduced with permission from Ref. [41]. Copyright 2018, American Chemistry Society. 
a

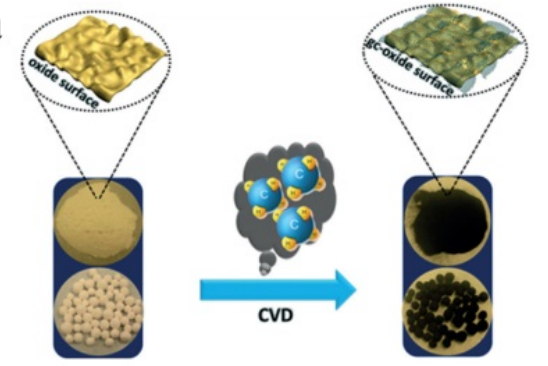

d

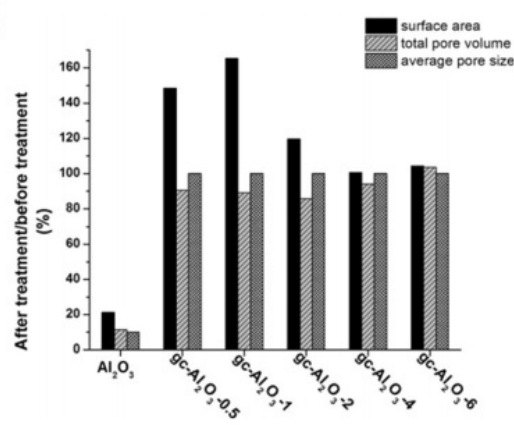

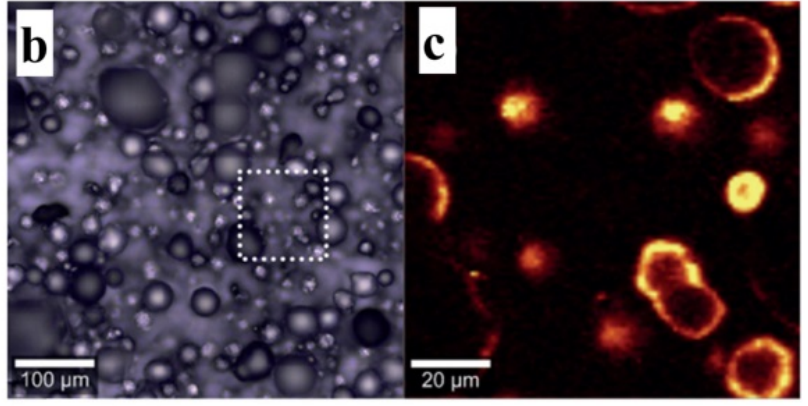

$\mathbf{e}$

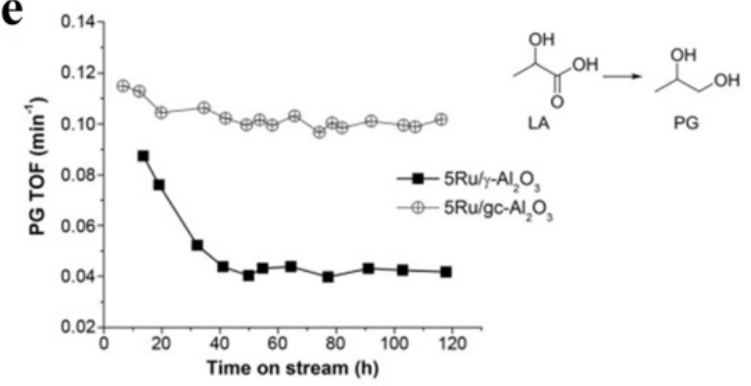

Fig. 13. (a) Preparation of the graphitic carbon/oxide composite ( $\left.\mathrm{gc}-\gamma-\mathrm{Al}_{2} \mathrm{O}_{3}\right)$ by chemical vapor deposition. (b) An optical micrograph of the gc- $\gamma-\mathrm{Al}_{2} \mathrm{O}_{3}$ sample. (c) A Raman spectroscopy map of the region marked by the box in panel (b). (d) Relative SAs, total pore volumes, and average particle sizes of the $\gamma-\mathrm{Al}_{2} \mathrm{O}_{3}$ and gc- $\gamma-\mathrm{Al}_{2} \mathrm{O}_{3}$ catalysts before and after the hydrothermal treatment (expressed in \%). (e) Specific propylene glycol formation rates plotted as functions of the time on stream for the two Ru catalysts ( $5 \mathrm{wt} \% \mathrm{Ru}$ ) during the liquid-phase hydrogenation of lactic acid to propylene glycol at a temperature of $120^{\circ} \mathrm{C}$ and $\mathrm{H}_{2}$ pressure of $500 \mathrm{psi}$ (5 wt\% lactic acid/ $\left.\mathrm{H}_{2} \mathrm{O}\right)$. Reproduced with permission from Ref. [121]. Copyright 2015, Wiley-VCH.

demonstrated that La doping helped $\mathrm{ZrO}_{2}$ reach a stable state during the reaction process. As a result, $\mathrm{Co} / \mathrm{ZrLa}_{0.5} \mathrm{O}_{x}$ maintained high stability after four recycling tests.

\subsection{2. $\quad$ Coating}

To avoid the corrosion of oxide supports, the fabrication of a core-shell structure containing an oxide core and a carbon shell has been considered an effective catalyst stabilization strategy because the carbon shell can act as an efficient barrier suppressing oxide transformation. Xiong and co-workers [121] coated $\gamma-\mathrm{Al}_{2} \mathrm{O}_{3}$ pellets with a graphitic carbon layer (denoted gc- $\gamma-\mathrm{Al}_{2} \mathrm{O}_{3}$ ) via chemical vapor deposition (Figs. 13(a)-(c)). No changes were observed for the synthesized gc- $\gamma-\mathrm{Al}_{2} \mathrm{O}_{3}$ catalyst after the water treatment at $220^{\circ} \mathrm{C}$ for $12 \mathrm{~h}$, while the uncoated $\gamma-\mathrm{Al}_{2} \mathrm{O}_{3}$ pellets collapsed and lost $80 \%$ of their surface area under the same conditions (Fig. 13(d)). After loading Ru NPs, the obtained $\mathrm{Ru} / \mathrm{gc}-\gamma-\mathrm{Al}_{2} \mathrm{O}_{3}$ catalyst for lactic acid conversion (Fig. 13(e)) was significantly more stable than $\mathrm{Ru} / \gamma-\mathrm{Al}_{2} \mathrm{O}_{3}$ catalyst. The described stabilization strategy can be extended to other oxide supports. Thus, Gatti and co-workers [122] prepared a $\mathrm{Ru} / \mathrm{SiO}_{2}-\mathrm{C}$ composite with a $\mathrm{SiO}_{2}$ core and a carbon shell. After using it to convert glycerol in water at $200{ }^{\circ} \mathrm{C}$, no changes in the catalyst structure occurred, and its composite support was more stable than the support of the uncoated $\mathrm{Ru} / \mathrm{SiO}_{2}$ catalyst. Similar results were obtained by Wan's group [123] and Shanks's group [124], which used hybrid SBA-15 and carbonaceous composites to load Pd NPs. The resulting catalysts exhibited negligible metal leaching after 20 cycles of chlo- robenzene aqueous-phase coupling and furfural hydrogenation.

\subsubsection{Hybridization}

Hybridization is considered an efficient strategy to improve the stability of various oxides, including carbon oxide and oxide-oxide composites. The carbon oxide composites obtained by the pyrolysis of MOFs have many practical applications $[125,126]$. For instance, Cao and co-workers $[127,128]$ prepared a $\mathrm{ZrO}_{2} @ \mathrm{C}$ composite from UIO-66 MOF followed by loading Ru or Ir as the active component. This composite was applied to the hydrogenation of levulinic acid in water (Fig. 14). The structure of the resultant Ru/ZrO $\mathrm{Z}_{2} @ \mathrm{C}$ or Ir/ZrO ${ }_{2} @ \mathrm{C}$ catalyst can be described as a strawberry cake, in which carbon is the cream, the strawberry consists of $\mathrm{ZrO}_{2}$ species $(3.3 \mathrm{~nm})$ embedded in the cream, and Ru NPs are the strawberry seeds. The carbon substrate protects the $\mathrm{ZrO}_{2}$ component, and the strong interactions between Ru metal and the nano-tetragonal $\mathrm{ZrO}_{2}$ support make $\mathrm{Ru} / \mathrm{ZrO}_{2} @ \mathrm{C}$ catalyst very stable during the hydrogenation of levulinic acid (Fig. 14(f)) even under the harsh reactions conditions ( $\mathrm{pH}=1$, Fig. 14(g)).

Mixed oxides can be also used to enhance the catalyst performance. Because $\mathrm{TiO}_{2}$ is a water-tolerant material with excellent hydrothermal stability properties [129-132], it may be mixed with another oxide to increase its stability. For instance, Wang and co-workers [133] synthesized a mixed oxide $\left(\mathrm{Al}_{2} \mathrm{O}_{3}-\mathrm{TiO}_{2}\right)$, which was used as a support for $\mathrm{Ru}$-based catalysts. Relatively large amounts of $\mathrm{Ru}$ and $\mathrm{Al}$ leached into the 

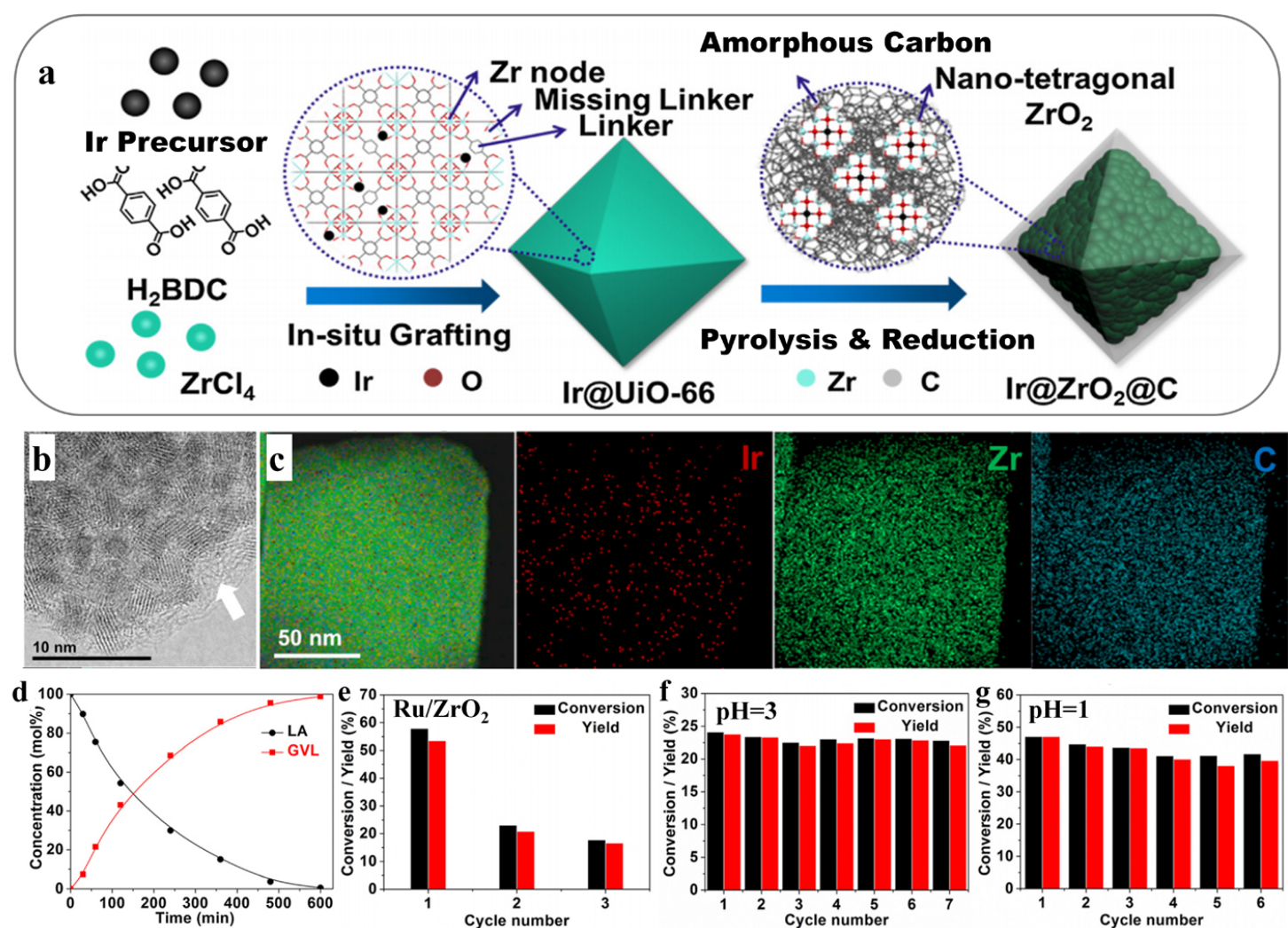

Fig. 14. (a) Schematic illustration of the in-situ synthesis of 0.6 wt $\%$ Ir@ $\mathrm{ZrO}_{2} @ \mathrm{C}$ catalyst. (b,c) High-resolution STEM image and EDX maps of Ir@ZrO ${ }_{2} @ \mathrm{C}$ catalyst. (d) Time profiles of the catalytic conversion of 10 wt\% levulinic acid in water over 0.6 wt\% Ir@ZrO ${ }_{2} @ \mathrm{C}$ catalyst. Results of the recycling experiments conducted for (e) 0.6 wt\% $\mathrm{Ir} / \mathrm{ZrO}_{2}$ (20 min), (f) 0.6 wt\% Ir@ZrO $@$ @C (1 h) in a pH = 3 aqueous solution, and (g) 0.6 wt\% Ir@ZrO $\mathrm{Zn}_{2} @ \mathrm{C}(1 \mathrm{~h})$ in a pH = 1 aqueous solution. Reaction conditions: $T=180{ }^{\circ} \mathrm{C}, P_{\mathrm{H} 2}=4 \mathrm{MPa}$, aqueous solution of 10 wt $\%$ levulinic acid. Reproduced with permission from Ref. [128]. Copyright 2019, Elsevier.

solution when $\mathrm{Ru} / \mathrm{Al}_{2} \mathrm{O}_{3}$ catalyst was employed for the hydrogenation of levulinic acid. In contrast, $\mathrm{Ru} / \mathrm{Al}_{2} \mathrm{O}_{3}-\mathrm{TiO}_{2}$ remained stable after a continuous reaction, owing to the synergistic effect of the $\mathrm{Al}_{2} \mathrm{O}_{3}$ and $\mathrm{TiO}_{2}$ components that considerably increased the stability of the pristine $\mathrm{Al}_{2} \mathrm{O}_{3}$ support.

\subsection{Optimization of reaction conditions}

As mentioned above, the corrosion and collapse of catalyst supports easily occur at high reaction temperatures in a water medium. Therefore, low reaction temperatures or mixed organic chemicals can slow down the catalyst deactivation to a certain extent. As pointed out by Li and co-workers [134], lower temperatures may suppress leaching, thus increasing the catalyst service life. Kasar and co-workers [135] showed that the solvent consisting of a methanol-water mixture (95:5) sig-

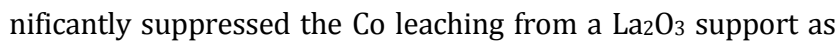
compared with that observed for pure water solvent during the hydrogenation of levulinic acid to gamma-velerolactone. Similarly, Hengne and co-workers [50] considerably increased the catalyst stability by replacing water with methanol. Thus, designing a highly stable catalyst with excellent intrinsic activity properties remains a very important task.

\section{Summary and outlook}

Biomass is the most abundant bio-renewable resource with high potential for the sustainable production of fine chemicals and fuels. It is currently processed by the catalytic conversion in an aqueous phase. However, the stability of heterogeneous metal catalysts in water is usually very low. Therefore, the development of catalysts with high activity and stability is a key step in the aqueous hydrogenation conversion of biomass-derived chemicals. Herein, we discussed various strategies for the preparation of highly stable catalysts from the following two aspects: (1) stabilization of MNPs by their encapsulation and confinement (interfacial or nanospace) and (2) stabilization of the catalyst support through chemical modification, coating, or hybridization.

Despite the significant progress made in this area, several challenges remain. For instance, the effect of carbon coating on the mass transfer of reactants (especially large molecules) is a problem that has to be solved, although the coating structure can protect NPs from the external chemical and physical environments and effectively increase the stability of metal catalysts. The active sites of a catalyst characterized by excellent performance during the aqueous hydrogenation of biomass must be fully exposed to facilitate the access of reactant molecules and increase the catalyst stability. Therefore, it is particularly important to maximize the exposure area of metal active centers to enhance the interactions between MNPs and the carbon support. Supported MPNs catalysts primarily include 
metal atoms bound to the carbon matrix through covalent or coordination bonds, and the strong metal-matrix interfacial interactions allow manipulations of the electronic structure aimed to increase the stability of the metal active sites. These attributes play an important role in regulating the ultimate catalyst activity and hydrothermal stability during the aqueous-phase biomass conversion. The MNP-matrix interfacial interactions can be further enhanced to enable more control over the catalyst activity and stability. For this purpose, interfacial engineering of MNPs and the support matrix must be performed from the synthetic and structural characterization perspectives, which will be the focus of future studies.

\section{References}

[1] P. Sudarsanam, E. Peeters, E. V. Makshina, V. I. Parvulescu, B. F. Sels, Chem. Soc. Rev., 2019, 48, 2366-2421.

[2] P. Sudarsanam, R. Y. Zhong, S. Van den Bosch, S. M. Coman, V. I. Parvulescu, B. F. Sels, Chem. Soc. Rev., 2018, 47, 8349-8402.

[3] F. H. Isikgor, C. R. Becer, Polym. Chem., 2015, 6, 4497-4559.

[4] M. Besson, P. Gallezot, C. Pinel, Chem. Rev., 2014, 114, 1827-1870.

[5] T. Kitanosono, K. Masuda, P. Y. Xu, S. Kobayashi, Chem. Rev., 2018, 118, 679-746.

[6] K. J. Wu, Y. L. Wu, Y. Chen, H. Chen, J. L. Wang, M. D. Yang, ChemSusChem, 2016, 9, 1355-1385.

[7] J. Niemeier, R. V. Engel, M. Rose, Green Chem., 2017, 19, 2839-2845.

[8] W. G. Guo, X. H. Liu, Y. Liu, C. Li, ACS Catal., 2017, 8, 328-341.

[9] C. Q. Zhu, S. Kais, X. C. Zeng, J. S. Francisco, I. Gladich, J. Am. Chem. Soc., 2017, 139, 27-30.

[10] F. Scalambra, N. Holzmann, L. Bernasconi, S. Imberti, A. Romerosa, ACS Catal., 2018, 8, 3812-3819.

[11] H. V. Tran, H. A. Doan, B. D. Chandler, L. C. Grabow, Curr. Opin. Chem. Eng., 2016, 13, 100-108.

[12] A. J. R. Hensley, Y. Wang, D. H. Mei, J.-S. McEwen, ACS Catal., 2018, 8, 2200-2208.

[13] X. H. Zhang, T. E. Sewell, B. Glatz, S. Sarupria, R. B. Getman, Catal. Today, 2017, 285, 57-64.

[14] C. Michel, J. Zaffran, A. M. Ruppert, J. Matras-Michalska, M. Jedrzejczyk, J. Grams, P. Sautet, Chem. Commun., 2014, 50, 12450-12453.

[15] X. M. Ren, M. Guo, H. Li, C. B. Li, L. Yu, J. Liu, Q. H. Yang, Angew. Chem. Int. Ed., 2019, 58, 14483-14488.

[16] H. Olcay, Y. Xu, G. W. Huber, Green Chem., 2014, 16, 911-924.

[17] Z. Zhao, R. Bababrik, W. H. Xue, Y. P. Li, N. M. Briggs, D.-T. Nguyen, U. Nguyen, S. P. Crossley, S. W. Wang, B. Wang, D. E. Resasco, Nature Catal., 2019, 2, 431-436.

[18] X. Y. Zhou, Z. P. Feng, W. W. Guo, J. M. Liu, R. Y. Li, R. Z. Chen, J. Huang, Ind. Eng. Chem. Res., 2019, 58, 3988-3993.

[19] M. Hronec, K. Fulajtarová, Catal. Commun., 2012, 24, 100-104.

[20] P. Jia, X. C. Lan, X. D. Li, T. F. Wang, ACS Sus. Chem. Eng., 2019, 7, 15221-15229.

[21] A. Osatiashtiani, A. F. Lee, K. Wilson, J. Chem. Technol. Biotechnol., 2017, 92, 1125-1135.

[22] Z. Y. Guo, C. X. Xiao, R. V. Maligal-Ganesh, L. Zhou, T. W. Goh, X. L. Li, D. Tesfagaber, A. Thiel, W. Y. Huang, ACS Catal., 2014, 4, 1340-1348.

[23] S. H. Zhu, Y. L. Zhu, S. L. Hao, H. Y. Zheng, T. Mo, Y. W. Li, Green Chem., 2012, 14, 2607-2616.

[24] C. B. Chen, M. Y. Chen, B. Zada, Y. J. Ma, L. Yan, Q. Xu, W. Z. Li, Q. X. Guo, Y. Fu, RSC Adv., 2016, 6, 112477-112485.
[25] M. Guo, C. Li, Q. H. Yang, Catal. Sci. Technol., 2017, 7, 2221-2227.

[26] C. T. Wang, Z. Q. Liu, L. Wang, X. Dong, J. Zhang, G. X. Wang, S. C. Han, X. J. Meng, A. M. Zheng, F.-S. Xiao, ACS Catal., 2017, 8, 474-481.

[27] S. C. Patankar, G. D. Yadav, ACS Sus. Chem. Eng., 2015, 3, 2619-2630.

[28] J. L. Zhang, K. G. Gao, S. L. Wang, W. Li, Y. Han, RSC Adv., 2017, 7, 6447-6456.

[29] Z. P. Yan, L. Lin, S. J. Liu, Energy Fuels, 2009, 23, 3853-3858.

[30] S. P. Li, Y. Y. Wang, Y. D. Yang, B. F. Chen, J. Tai, H. Z. Liu, B. X. Han, Green Chem., 2019, 21, 770-774.

[31] Z. Meng, Y. Liu, G. X. Yang, Y. H. Cao, H. J. Wang, F. Peng, P. F. Liu, H. Yu, ACS Sus. Chem. Eng., 2019, 7, 16501-16510.

[32] X. D. Zhang, P. Zhang, C. J. Chen, J. L. Zhang, G. Y. Yang, L. R. Zheng, J. Zhang, B. X. Han, Green Chem., 2019, 21, 54-58.

[33] S. B. Tian, Z. Y. Wang, W. B. Gong, W. X. Chen, Q. C. Feng, Q. Xu, C. Chen, C. Chen, Q. Peng, L. Gu, H. J. Zhao, P. Hu, D. S. Wang, Y. D. Li, J. Am. Chem. Soc., 2018, 140, 11161-11164.

[34] M. G. Prakash, R. Mahalakshmy, K. R. Krishnamurthy, B. Viswanathan, Catal. Today, 2016, 263, 105-111.

[35] S. H. Zhu, Y. L. Cen, J. Guo, J. C. Chai, J. G. Wang, W. B. Fan, Green Chem., 2016, 18, 5667-5675.

[36] M. Modelska, M. J. Binczarski, Z. Kaminski, S. Karski, B. Kolesinska, P. Mierczynski, C. J. Severino, A. Stanishevsky, I. A. Witonsha, Catalysts, 2020, 10, 4, 444.

[37] S. H. Zhu, Y. F. Xue, J. Guo, Y. L. Cen, J. G. Wang, W. B. Fan, ACS Catal., 2016, 6, 2035-2042.

[38] H. C. Zhou, J. L. Song, H. L. Fan, B. B. Zhang, Y. Y. Yang, J. Y. Hu, Q. G. Zhu, B. X. Han, Green Chem., 2014, 16, 3870-3875.

[39] Z. Z. Wei, Y. Q. Chen, J. Wang, D. F. Su, M. H. Tang, S. J. Mao, Y. Wang, ACS Catal., 2016, 6, 5816-5822.

[40] L. Jiang, P. Zhou, C. J. Liao, Z. H. Zhang, S. W. Jin, ChemSusChem, 2018, 11, 959-964.

[41] Y. F. Ma, G. Y. Xu, H. Wang, Y. X. Wang, Y. Zhang, Y. Fu, ACS Catal., 2018, 8, 1268-1277.

[42] H. N. Li, C. Y. Cao, J. Liu, Y. Shi, R. Si, L. Gu, W. G. Song, Sci. China Mater., 2019, 62, 1306-1314.

[43] K. Murugesan, A. S. Alshammari, M. Sohail, R. V. Jagadeesh, ACS Sus. Chem. Eng., 2019, 7, 14756-14764.

[44] G. Novodarszki, H. E. Solt, J. Valyon, F. Lonyi, J. Hancsok, D. Deka, R. Tuba, M. R. Mihalyi, Catal. Sci. Technol., 2019, 9, 2291-2304.

[45] L. M. Ning, S. Y. Liao, H. Li, R. Y. Tong, C. Q. Dong, M. T. Zhang, W. Gu, X. Liu, Carbon, 2019, 154, 48-57.

[46] S. S. R. Gupta, M. L. Kantam, Catal. Today, 2018, 309, 189-194.

[47] S. N. Son, D. Le, ACS Sus. Chem. Eng., 2019, 47, 45-52.

[48] L. Huang, Y. L. Zhu, C. F. Huo, H. Y. Zheng, G. Feng, C. H. Zhang, Y. W. Li, J. Mol. Catal. A, 2008, 288, 109-115.

[49] T. Jiang, Y. X. Zhou, S. G. Liang, H. Z. Liu, B. X. Han, Green Chem., 2009, 11, 1000-1006.

[50] A. M. Hengne, C. V. Rode, Green Chem., 2012, 14, 1064-1072.

[51] K. Yan, J. Y. Liao, X. Wu, X. M. Xie, RSC Adv., 2013, 3, 3853-3856.

[52] S. H. Zhu, X. Q. Gao, Y. L. Zhu, W. B. Fan, J. G. Wang, Y. W. Li, Catal. Sci. Technol., 2015, 5, 1169-1180.

[53] D. R. Jones, S. Iqbal, S. Ishikawa, C. Reece, L. M. Thomas, P. J. Miedziak, D. J. Morgan, J. K. Edwards, J. K. Bartley, D. J. Willock, G. J. Hutchings, Catal. Sci. Technol., 2016, 6, 6022-6030.

[54] J. L. Zheng, J. H. Zhu, X. Xu, W. M. Wang, J. W. Li, Y. Zhao, K. J. Tang, Q. Song, X. L. Qi, D. J. Kong, Y. Tang, Sci. Rep., 2016, 6, 28898.

[55] R. R. Gowda, E. Y. X. Chen, ChemSusChem, 2016, 9, 181-185.

[56] I. Sádaba, M. López Granados, A. Riisager, E. Taarning, Green Chem., 2015, 17, 4133-4145.

[57] T. W. Hansen, A. T. De la Riva, S. R. Challa, A. K. Datye, Acc. Chem. 


\section{Graphical Abstract}

Chin. J. Catal., 2021, 42: 694-709 doi: 10.1016/S1872-2067(20)63699-3

\section{Stabilization of heterogeneous hydrogenation catalysts for the aqueous-phase reactions of renewable feedstocks}

Xiaoyan Liu, Guojun Lan * Zhenqing Li, Lihua Qian, Jian Liu, Ying Li * Zhejiang University of Technology, China; Dalian Institute of Chemical Physics, Chinese Academy of Sciences, China; University of Surrey, UK

The graphical abstract summarizes the described confinement strategies for improving the stability of metal catalysts (especially MNPs), such as the application of an ultrathin layer covered and encapsulation for the nanospace confinement and embedment, and attachment of organic groups and heteroatoms for the interfacial confinement.

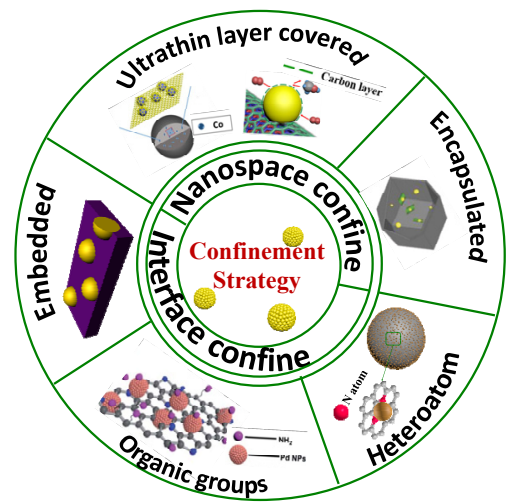

teiro, J. Liu, NPG Asia Mater., 2016, 8, e240-e240.

Res., 2013, 46, 1720-1730.

[58] R. M. Ravenelle, J. R. Copeland, A. H. Van Pelt, J. C. Crittenden, C. Sievers, Top. Catal., 2012, 55, 162-174.

[59] X. B. Fan, Z. Y. Tao, C. X. Xiao, F. Liu, Y. Kou, Green Chem., 2010, 12, 795-797.

[60] H. Wang, Y. Kou, Chin. J. Catal., 2013, 34, 1914-1925.

[61] A. K. Dalai, B. H. Davis, Appl. Catal. A, 2008, 348, 1-15.

[62] X. Y. Liu, G. J. Lan, Y. Boyjoo, L. H. Qian, S. Gu, C. A. H. Price, L. Wang, Y. Li, J. Liu, Chem. Engin. J., 2019, 374, 895-903.

[63] B. L. Li, L. L. Li, C. Zhao, Green Chem., 2017, 19, 5412-5421.

[64] K. I. Shimizu, S. Kanno, K. Kon, Green Chem., 2014, 16, 3899-3903.

[65] P. A. Son, S. Nishimura, K. Ebitani, RSC Adv., 2014, 4, 10525-10530.

[66] T. Subramanian, K. Pitchumani, ChemCatChem, 2012, 4, 1917-1921.

[67] J. Wang, S. Jaenicke, G. K. Chuah, RSC Adv., 2014, 4, 13481-13489.

[68] F. J. Liu, K. Huang, A. M. Zheng, F.-S. Xiao, S. Dai, ACS Catal., 2018, 8, 372-391.

[69] H. N. Pham, A. E. Anderson, R. L. Johnson, T. J. Schwartz, B. J. O'Neill, P. Duan, K. Schmidt-Rohr, J.A. Dumesic, A. K. Datye, ACS Catal., 2015, 5, 4546-4555.

[70] M. El Doukkali, A. Iriondo, J. F. Cambra, I. Gandarias, L. Jalowiecki-Duhamel, F. Dumeignil, P. L. Arias, Appl. Catal. A, 2014, 472, 80-91.

[71] Y. J. Pagán-Torres, J. M. R. Gallo, D. Wang, H. N. Pham, J. A. Libera, C. L. Marshall, J. W. Elam, A. K. Datye, J. A. Dumesic, ACS Catal., 2011, 1, 1234-1245.

[72] S. Prodinger, H. Shi, S. Eckstein, J. Z. Hu, M. V. Olarte, D. M. Camaioni, M. A. Derewinski, J. A. Lercher, Chem. Mater., 2017, 29, 7255-7262.

[73] C. Nguyen-Huy, H. Lee, J. Lee, J. H. Kwak, K. An, Appl. Catal. A, 2019, 571, 118-126.

[74] M. Guo, G. J. Lan, J. Peng, M. R. Li, Q. H. Yang, C. Li, J. Mater. Chem. A, 2016, 4, 10956-10963.

[75] A. M. Ruppert, M. Jędrzejczyk, O. Sneka-Płatek, N. Keller, A. S. Dumon, C. Michel, P. Sautet, J. Grams, Green Chem., 2016, 18, 2014-2028.

[76] T. Y. Yang, H. Ling, J.-F. Lamonier, M. Jaroniec, J. Huang, M. J. Mon-
[77] C. X. Xiao, T.-W. Goh, Z. Y. Qi, S. Goes, K. Brashler, C. Perez, W. Y. Huang, ACS Catal., 2016, 6, 593-599.

[78] J. L. Figueiredo, M. F. R. Pereira, M. M. A. Freitas, J. J. M Órfão, Carbon, 1999, 37, 1379-1389.

[79] J. A. Menendez, J. J. Pis, Afinidad, 1998, 55, 315-325.

[80] J. L. Figueiredo, M. F. R. Pereira, Catal. Today, 2010, 150, 2-7.

[81] G. Q. Feng, G. J. Lan, Y. Li, W. F. Han, H. Z. Liu, Chin. J. Catal., 2012, 33, 1191-1197.

[82] J. Jaramillo, P. M. Alvarez, V. Gómez-Serrano, Fuel Processing Technol., 2010, 91, 1768-1775.

[83] Y. Li, G. J. Lan, G. Q. Feng, W. Jiang, W. F. Han, H. D. Tang, H. Z. Liu, ChemCatChem, 2014, 6, 572-579.

[84] Y. Li, C. G. Pan, W. F. Han, H. F. Chai, H. Z. Liu, Catal. Today, 2011, 174, 97-105.

[85] H. P. Boehm, Carbon, 1994, 32, 759-769.

[86] A. E. Aksoylu, M. M. A. Freitas, J. L. Figueiredo, Appl. Catal. A, 2000, $192,29-42$.

[87] A. Ferry, K. Schaepe, P. Tegeder, C. Richter, K. M. Chepiga, B. J. Ravoo, F. Glorius, ACS Catal, 2015, 5, 5414-5420.

[88] Z. Z. Wang, C. P. Wang, S. J. Mao, Y. T. Gong, Y. Z. Chen, Y. Wang, J. Mater. Chem. A, 2019, 7, 25791-25795.

[89] Y. L. Cao, S. J. Mao, M. M. Li, Y. Q. Chen, Y. Wang, ACS Catal., 2017, 7, 8090-8112.

[90] M. Sun, X. B. Wu, Z. Y. Xie, X. T. Deng, J. Y. Wen, Q. Z. Huang, B. Y. Huang, Carbon, 2017, 125, 401-408.

[91] V. Perazzolo, R. Brandiele, C. Durante, M. Zerbetto, V. Causin, G. A. Rizzi, I. Cerri, G. Granozzi, A. Gennaro, ACS Catal., 2018, 8, $1122-1137$.

[92] Q. C. Feng, S. Zhao, Q. Xu, W. X. Chen, S. B. Tian, Y. Wang, W. S. Yan, J. Luo, D. S. Wang, Y. D. Li, Adv. Mater., 2019, 31, 36, 1901024.

[93] W. C. Cheong, W. J. Yang, J. Zhang, Y. Li, D. Zhao, S. J. Liu, K. L. Wu, Q. G. Liu, C. Zhang, D. S. Wang, Q. Peng, C. Chen, Y. D. Li, ACS Appl. Mater. Interfaces, 2019, 11, 33819-33824.

[94] W. B. Gong, Q. L. Yuan, C. Chen, Y. Lv, Y. Lin, C. H. Liang, G. Z. Wang, H. M. Zhang, H. J. Zhao, Adv. Mater., 2019, 31, 49, 1906051.

[95] Z. Gao, C. Y. Li, G. L. Fan, L. Yang, F. Li, Appl. Catal. B, 2018, 226, 523-533.

[96] X. J, Cui, A. E. Surkus, K. Junge, C. Topf, J. Radnik, C. Kreyenschulte, M. Beller, Nat. Commun., 2016, 7, 11326. 
[97] F. Yang, D. H. Deng. X. L. Pan, Q. Fu, X. H. Bao, Nat. Sci. Rev., 2015, 2, 183-201.

[98] J. Z. Li, X. F. Bai, H. F. Lv, Microporous Mesoporous Mater., 2019, 275, 69-75.

[99] H. R. Chen, K. Shen, Q. Mao, J. Y. Chen, Y. W. Li, ACS Catal., 2018, 8, 1417-1426.

[100] H. Tian, F. Huang, Y. H. Zhu, S. M. Liu, Y. Han, M. Jaroniec, Q. H. Yang, H. Y. Liu, G. Q. Lu, J. Liu, Adv. Funt. Mater., 2018, 28, 1801737.

[101] H. Tian, X. Y. Liu, L. B. Dong, X. M. Ren, H. Liu, C. A. H. Price, Y. Li, G. X. Wang, Q. H. Yang, J. Liu, Adv. Sci., 2019, 6, 22, 1900807.

[102] H. Y. Liu, J. Wang, Z. B. Feng, Y. M. Lin, L. Y. Zhang, D. S. Su, Small, 2015, 11, 5059-5064.

[103] Y. Yang, F. Yang, D. H. Zeng, Z. L. Huang, J. P. Zhang, S. J. Hao, X. G. Kong, Z. B. Zhang, B. J. Liu, J. Colloid Interfaces Sci., 2018, 531, 291-299.

[104] G. Gao, P. Sun, Y. Q. Li, F. Wang, Z. L. Zhao, Y. Qin, F. W. Li, ACS Catal., 2017, 7, 4927-4935.

[105] W. Luo, S. Zafeiratos, ChemCatChem, 2017, 9, 2432-2442.

[106] X. Tong, J. M. Zhang, G. X. Zhang, Q. L. Wei, R. Chenitz, J. P. Claverie, S. H. Sun, Chem. Mater., 2017, 29, 9579-9587.

[107] Y. Long, S. Y. Song, J. Li, L. L. Wu, Q. S. Wang, Y. Liu, R. C. Jin, H. J. Zhang, ACS Catal., 2018, 8, 8506-8512.

[108] L. Tang, X. G. Meng, D. H. Deng, X. H. Bao, Adv. Mater., 2019, 31, 50, 1901996.

[109] S. H. Zheng, X. Y. Shi, P. Das, Z.-S. Wu, X. H. Bao, Adv. Mater., 2019, 31, 50, 1900583.

[110] Y. L. Cao, B. W. Zhao, X. B. Bao, Y. Wang, ACS Catal., 2018, 8, 7077-7085.

[111] X. Y. Liu, G. J. Lan, P. P. Su, L. H. Qian, T. R. Reina, L. Wang, Y. Li, J. Liu, Catal. Today, 2020, 351, 75-82.

[112] Z. L. Jiang, G. J. Lan, X. Y. Liu, H. D. Tang, Y. Li, Catal. Sci. Technol., 2016, 6, 7259-7266.

[113] Y. Li, G. J. Lan, H. Y. Wang, H. D. Tang, X. H. Yan, H. Z. Liu, Catal. Commun., 2012, 20, 29-35.

[114] G. J. Lan, H. D. Tang, Y. P. Zhou, W. F. Han, H. Z. Liu, X. N. Li, Y. Li, ChemCatChem, 2014, 6, 353-360.

[115] Z. J. Wei, J. T. Lou, C. M. Su, D. C. Guo, Y. X. Liu, S. G. Deng, ChemSusChem, 2017, 10, 1720-1732.

[116] H. H. Yang, R. F. Nie, W. Xia, X. L. Yu, D. F. Jin, X. H. Lu, D. Zhou, Q. H. Xia, Green Chem., 2017, 19, 5714-5722.

[117] S. Ishikawa, D. R. Jones, S. Iqbal, C. Reece, D. J. Morgan, D. J.
Willock, P. J. Miedziak, J. K. Bartley, J. K. Edwards, T. Murayama, W. Ueda, G. J. Hutchings, Green Chem., 2017, 19, 225-236.

[118] T. Y. Deng, L. Yan, X. L. Li, Y. Fu, ChemSusChem, 2019, 12, 3837-3848.

[119] K. Q. Sun, Y. C. Hong, G. R. Zhang, B.-Q. Xu, ACS Catal., 2011, 1, 1336-1346.

[120] H. Ait Rass, N. Essayem, M. Besson, ChemSusChem, 2015, 8, 1206-1217.

[121] H. Xiong, T. J. Schwartz, N. I. Andersen, J. A. Dumesic, A. K. Datye, Angew. Chem. Int. Ed., 2015, 54, 7939-7943.

[122] M. N. Gatti, B. Lombardi, D. Gazzoli, G. F. Santori, F. Pompeo, N. N. Nichio, Catalysts, 2017, 7, 1, UNSP 6.

[123] Y. Wan, H. Y. Wang, Q. F. Zhao, M. Klingstedt, O. Terasaki, D. Y. Zhao, J. Am. Chem. Soc., 2009, 131, 4541-4550.

[124] J. J. Huo, R. L. Johnson, P. Duan, H. N. Pham, D. Mendivelso-Perez, E. A. Smith, A. K. Datye, K. Schmidt-Rohr, B. H. Shanks, Catal. Sci. Technol., 2018, 8, 1151-1160.

[125] X. Wang, W. X. Chen, L. Zhang, T. Yao, W. Liu, Y. Lin, H. X. Ju, J. C. Dong, L. R. Zheng, W. S. Yan, X. S. Zheng, Z. J. Li, X. Q. Wang, J. Yang, D. S. He, Y. Wang, Z. X. Deng, Y. E. Wu, Y. D. Li, J. Am. Chem. Soc., 2017, 139, 9419-9422.

[126] P. Wang, J. Feng, Y. P. Zhao, S. Gu, J. Liu, RSC Adv., 2017, 7, 55920-55926.

[127] W. X. Cao, W. H. Luo, H. G. Ge, Y. Su, A. Q. Wang, T. Zhang, Green Chem., 2017, 19, 2201-2211.

[128] W. X. Cao, L. Lin, H. F. Qi, Q. He, Z. J. Wu, A. Q. Wang, W. H. Luo, T. Zhang, J. Catal., 2019, 373, 161-172.

[129] G. M. Dhar, B. N. Srinivas, M. S. Rana, M. Kumar, S. K. Maity, Catal. Today, 2003, 86, 45-60.

[130] R. He, X. L. Huang, P. Zhao, B. Han, T. H. Wu, Y. Wu, Waste Biomass Valori., 2018, 9, 657-668.

[131] J. J. Tan, J. L. Cui, T. S. Deng, X. J. Cui, G. Q. Ding, Y. L. Zhu, Y. W. Li, ChemCatChem, 2015, 7, 508-512.

[132] J. Z. Duan, Y. T. Kim, H. Lou, G. W. Huber, Catal. Today, 2014, 234, 66-74.

[133] R. F. Wang, L. G. Chen, X. H. Zhang, Q. Zhang, Y. P. Li, C. G. Wang, L. L. Ma, RSC Adv., 2018, 8, 40989-40995.

[134] G. Q. Li, H. H. Yang, M. Cheng, W. Hu, L. H. Tian, W. X. Mao, R. F. Nie, Mol. Catal., 2018, 455, 95-102.

[135] G. B. Kasar, N. S. Date, P. N. Bhosale, C. V. Rode, Energy Fuels, 2018, 32, 6887-6900.

\section{用于生物质水相加氢多相负载型金属催化剂的稳定策略 \\ 刘晓艳 ${ }^{\mathrm{a}, \mathrm{b}}$, 蓝国钧, ${ }^{\mathrm{a},}$, 李振清 ${ }^{\mathrm{a}}$, 钱丽华 ${ }^{\mathrm{a}}$, 刘 健 ${ }^{\mathrm{b}, \mathrm{c}}$, 李 瑛, \\ $a^{a}$ 浙江工业大学工业催化研究所, 浙江杭州 310032 , 中国

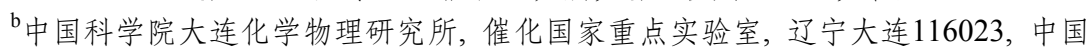 \\ “萨里大学先进科技研究所, 大连化物所-萨里大学未来材料研究中心, 吉尔福德萨里GU27XH, 英国}

摘要: 生物质是天然的可再生能源和资源, 具有来源广泛、储量丰富、价格低廉的优点以及可转化为高附加值化学品的多 功能性, 因此作为传统化石能源替代材料受到广泛关注和研究. 将生物质通过催化转化为平台化合物再进一步利用是生 物质利用的重要途径, 其中催化加氢是常用的反应之一. 由于绝大多数生物质平台化合物分子中都含氧元素, 其加氢过程 中会不可避免的产生水, 同时水作为绿色环保, 价廉易得的溶剂, 可以溶解绝大多数生物质平台化合物, 因此选择水做溶剂 具有重要意义. 负载型纳米金属催化剂(如 $\mathrm{Au} 、 \mathrm{Rh} 、 \mathrm{Pt} 、 \mathrm{Pd} 、 \mathrm{Ru} 、 \mathrm{Cu}$ 和 $\mathrm{Co}$ 等)在生物质水相加氢反应中具有广泛的应用, 但 其在水相反应条件下(通常为高温、高压、强酸性等苛刻条件)容易在反应过程中发生纳米金属粒子的团聚、流失以及载体 的坍塌、结构转变等引起失活. 因此, 发展可以在水相体系中稳定的金属多相催化剂对生物质资源化利用非常必要.

本文首先综述了溶剂水对反应的影响以及负载型金属催化剂在水相体系中的失活类型与机理, 内容包括: (1)溶剂水对 
催化剂及催化加氢反应的积极作用, 包含提高转化率和影响产物选择性; (2)溶剂水引起催化剂失活的原因, 如引起金属纳 米粒子发生团聚、氧化、流失以及载体发生溶解、坍塌、结构转变等. 从负载型金属催化剂的失活机理入手, 分别从提高 金属纳米粒子的稳定性和载体的稳定性两个方向综述了提高负载型金属催化剂稳定性的普适性策略, 内容包括: (1)通过界 面限域策略增强金属-载体相互作用的方式提高金属纳米粒子在载体上的稳定性,包括有机基团配位、杂原子配位、镶嵌 法等; (2)通过空间限域策略将金属纳米颗粒封装的方式提高金属纳米粒子的稳定性,包括利用一维的空心管状材料、二维 的超薄材料以及三位的空心球(笼)材料等; (3)通过提高载体(主要为氧化物载体)的稳定性以提高催化剂整体稳定性, 包括 对载体进行修饰、包覆、杂化等方式. 本工作所综述的提高生物质水相加氢金属催化剂稳定性的策略为高稳定性催化剂 的设计指出了方向.

关键词: 生物质转化; 多相催化剂; 金属催化剂; 水相反应; 稳定性

收稿日期: 2020-05-27. 接受日期: 2020-07-01. 上网日期: 2020-09-22.

*通讯联系人. 电子信箱: languojun@zjut.edu.cn

\#通讯联系人. 电话: (0571)88320766; 传真: (0571)88320259; 电子信箱: liying@zjut.edu.cn

基金来源: 国家自然科学基金(21908197).

本文的电子版全文由Elsevier出版社在ScienceDirect上出版(http://www.sciencedirect.com/science/journal/18722067). 